\title{
The contractile apparatus and mechanical properties of airway smooth muscle
}

\author{
S.J. Gunst, D.D. Tang
}

The contractile apparatus and mechanical properties of airway smooth muscle. S.J. Gunst, D.D. Tang. C ERS Journals Ltd 2000.

ABSTRACT: The functional properties of airway smooth muscle are fundamental to the properties of the airways in vivo. However, many of the distinctive characteristics of smooth muscle are not easily accounted for on the basis of molecular models developed to account for the properties of striated muscles. The specialized ultrastructural features and regulatory mechanisms present in smooth muscle are likely to form the basis for many of its characteristic properties.

The molecular organization and structure of the contractile apparatus in smooth muscle is consistent with a model of force generation based on the relative sliding of adjacent actin and myosin filaments. In airway smooth muscle, actomyosin activation is initiated by the phosphorylation of the $20 \mathrm{kDa}$ light chain of myosin; but there is conflicting evidence regarding the role of myosin light chain phosphorylation in tension maintenance. Tension generated by the contractile filaments is transmitted throughout the cell via a network of actin filaments anchored at dense plaques at the cell membrane, where force is transmitted to the extracellular matrix via transmembrane integrins. Proteins bound to actin and/or localized to actin filament anchorage sites may participate in regulating the shape of the smooth muscle cell and the organization of its contractile filament system. These proteins may also participate in signalling pathways that regulate the crossbridge activation and other functions of the actin cytoskeleton.

The length-dependence of active force and the mechanical plasticity of airway smooth muscle may play an important role in determining airway responsiveness during lung volume changes in vivo. The molecular basis for the length-dependence of tension in smooth muscle differs from that in skeletal muscle, and may involve mechano-transduction mechanisms that modulate contractile filament activation and cytoskeletal organization in response to changes in muscle length. The reorganization of contractile filaments may also underlie the plasticity of the mechanical response of airway smooth muscle. Changes in the structural organization and signalling pathways of airway smooth muscle cells resulting form alterations in mechanical forces in the lung may be important factors in the development of pathophysiological conditions of chronic airway hyperresponsiveness.

Eur Respir J 2000; 15: 600-616.

Dept of Physiology and Biophysics, Indiana University School of Medicine, Indianapolis, IN, USA.

Correspondence: S.J. Gunst

Dept of Physiology and Biophysics

Indiana University School of Medicine

635 Barnhill Dr

Indianapolis

IN 46202-5126

USA

Fax: 13172743318

Keywords: Actomyosin

contractile properties

contractile proteins

length-dependence

mechanical plasticity

Received: December 221999

Accepted after revision January 122000

Supported by Public Health Service Grant \#HL29289
The mechanical properties of airway smooth muscle are fundamental to the regulation of airway contractility and airway tone in vivo. These mechanical properties have traditionally been interpreted in terms of the "sliding filament model" of muscle contraction first proposed by HuXley and Niedergerke [1] and HuXley and Hanson [2] to explain the contractile behaviour of skeletal muscle. Like other smooth muscles, airway smooth muscle exhibits the same hyperbolic force-velocity relationship that is characteristic of striated muscles, and the lengthtension relationship is also qualitatively similar to that of striated muscles [3]. The qualitative similarities between

For editorial comments see page 438 smooth and striated muscles have led to the suggestion that the functional behaviour of these muscles is rooted in similar mechanisms.

Clearly, the fundamental molecular mechanism of force development in both smooth and striated muscles is essentially the same. In both of these tissues, force production occurs as a result of the cyclical interaction of crossbridges between actin and myosin that causes the sliding of adjacent actin and myosin filaments with respect to one another. However, smooth muscle tissues in general, and airway smooth muscle in particular, possess a number of distinctive functional properties that are not easily accounted for on the basis of mechanistic models developed to account for the properties of striated muscles. The unique 
ultrastructural features and regulatory mechanisms present in smooth muscle are likely to form the basis for contractile properties that differ significantly from those of striated muscles.

A wealth of information has been accumulated in the last few decades regarding the structure and regulation of the contractile apparatus of smooth muscle tissues; however, the information has been obtained using a diversity of smooth muscle tissue types. Although the structure and regulation of some components of the contractile apparatus may differ significantly among different smooth muscle tissue types; in many cases, information specific for airway muscle is not available. Thus, review of the molecular organization and regulation of the contractile apparatus of airway smooth muscle must necessarily rely substantially on information obtained from a variety of smooth muscle tissue types.

In the ensuing article, the authors will review the current status of knowledge regarding the ultrastructure and regulation of the contractile apparatus of airway smooth muscle and the molecular basis for the mechanical properties of this tissue. The authors will also consider how the basic mechanical properties of airway smooth muscle are reflected in the functional characteristics of the airways in vivo.

\section{Structure and organization of the contractile apparatus in airway smooth muscle cells}

\section{Cellular organization of contractile apparatus}

Contractile filament organization. The actin and myosin containing thick and thin filaments, the myofilaments, are generally considered to be the primary constituents of the contractile apparatus in smooth muscle cells. The thin filaments are $\sim 7 \mathrm{~nm}$ in diameter, and are composed primarily of actin. The relatively less abundant thick filaments are $12-15 \mathrm{~nm}$ in diameter, and are composed primarily of myosin. Actin filaments are arranged in hexagonal arrays that form cable-like bundles. The spaces around the actin filament bundles are occupied by myosin filaments [4-7]. In airway smooth muscle cells, bundles of parallel actin filaments are oriented along the long axis of the cell [8]. The ratio of actin to myosin filaments varies among different smooth muscle tissues, ranging from as low as $8: 1$ in chicken gizzard [9] to approximately $15: 1$ in vascular muscle [10], to as high as 50:1 in isolated amphibian visceral muscle [5]. There is no apparent lateral register between myofilaments in smooth muscle cells. No striations or regular repeats are visible by electron or light microscopy comparable to those observed in striated muscle tissues $[4,5]$.

A third type of filament, the intermediate filament $(\sim 10$ $\mathrm{nm}$ in diameter), is also a component of the contractile system in smooth muscle cells. In visceral smooth muscle, intermediate filaments are composed primarily of desmin [11]; whereas in vascular smooth muscle they are composed primarily of vimentin $[4,7,12,13]$. Desmin is a prominent constituent of airway smooth muscle [14]. Intermediate filaments are grouped into bundles that run the length of the cell and exhibit ramifications to the cell membranes [4, 7, 11-13, 15-17]. Intermediate filaments are much less numerous than the myofilaments [13], and are generally believed to play a structural role in maintaining the organization of the myofilament system.

Membrane-associated dense plaques. In electron micrographs, bundles of actin filaments and intermediate filaments can be seen penetrating the inner surface of electron dense areas of the membrane termed "dense bands" or "dense plaques" [4, 6, 18, 19]. Dense plaques (sometimes described as ribs) are oriented along the long axis of the cell membrane and alternate with membrane areas containing longitudinal rows of invaginated vesicles called surface caveolae [4, 18, 20, 21]. Dense bands are sometimes coupled to each other in adjacent cells at areas termed "attachment plaques". These membrane dense areas can also be visualized by immunofluorescence staining of vinculin, talin or $\alpha$-actinin $[22,23]$. The membrane-associated dense bands mediate the transmission of force between the contractile apparatus and the extracellular matrix (ECM), whereas attachment plaques provide mechanical coupling between the adjacent smooth muscle cells [20]. Because the actin filaments of smooth muscle cells terminate at points along the entire length of the cell membrane, the transmission of force in smooth muscle cells is diffused along the entire length and width of the cell surface, rather than being concentrated at a few loci within the cell.

The membrane dense plaques of smooth muscle cells are thought to be similar in their molecular composition to the focal adhesion sites of cultured cells [24]. The primary transmembrane components of these sites are transmembrane integrins, which attach to ECM proteins at one end and to cytoskeletal proteins at the other end. In nonmuscle cells, several dozen proteins that localize to these membrane adhesion sites have been identified. In smooth muscle, vinculin, talin, and $\alpha$-actinin, and paxillin have been localized to the membrane-associated dense plaque sites [18, 23, 25-28]. There is biochemical evidence that vinculin, talin, and $\alpha$-actinin function to link actin filaments to transmembrane integrins; however the exact nature of the molecular interactions that are involved in this linkage remains poorly understood [29-35]. Recent evidence suggests that in some nonmuscle cell types, the attachment of actin filaments to the membrane can be regulated in response to activation of the cell [34, 36, 37]; however, there is presently no direct evidence as to whether this occurs in smooth muscle cells.

Cytosolic dense bodies. Electron dense areas are also observed in the smooth muscle cell cytoplasm that are referred to as "dense bodies". They are obliquely oriented elongated structures up to $1.5 \mu \mathrm{m}$ in length that are distributed relatively uniformly throughout the cytoplasm $[6$, 15, 23, 38]. Actin filaments appear in association with virtually all cytoplasmic dense bodies. The decoration of actin filaments with myosin subfragments (S-1) indicates that the filaments are oriented with the right polarity for force generation (arrowheads pointing away from the dense bodies) $[15,38]$. The observation that actin filaments with opposite polarity extend from either side of a given dense body has led to the suggestion that the cytoplasmic dense bodies are functionally equivalent to the Z-bands of striated muscle.

Chains of dense bodies appear to be connected by intermediate filaments. Intermediate filaments can be seen 
on the lateral sides of dense bodies, often forming loops at the lateral surface $[15,38]$. The intermediate filaments that surround a given dense body do not run parallel to the contractile unit and associate with the next dense body in series; but are oriented obliquely toward another dense body of a different contractile unit. Laterally aligned dense bodies move rapidly toward one another during contraction, indicating that they are attached to contractile filaments. Whereas the regular geometric arrangement of dense bodies is retained during contraction, the intermediate filaments that link the dense bodies become crumpled and disordered $[16,38]$. Analysis of the movement of dense bodies in contracting isolated smooth muscle cells suggests that they provide mechanical coupling between the contractile apparatus, the cytoskeleton, and the cell surface $[16,28]$.

The molecular mechanisms that couple the contractile filaments to the dense bodies are not established. Dense bodies contain the actin-cross-linking protein, $\alpha$-actinin, as do the Z-lines of skeletal muscle. Dense bodies also contain actin and probably calponin [39-42]. Ultrastructural and biochemical data obtained by MABUCH et al. [43] suggests that calponin may couple actin filaments and intermediate filaments at dense bodies.

\section{The thick filaments of airway smooth muscle}

Structure and function of the myosin molecule. The thick filaments of smooth muscle are made up of monomeric myosin molecules that polymerize to form filaments. The structure of the smooth muscle myosin molecule is grossly similar to that of skeletal muscle myosin. It is a large asymmetric protein (molecular weight (MW) 520 kDa) that is made up of six polypeptide chains: two $\sim 205 \mathrm{kDa}$ heavy chains that form a dimer, and two pairs of light chains, the $20 \mathrm{kDa}$ "regulatory" light chains and the $17 \mathrm{kDa}$ "essential" light chains [44]. The myosin heavy chain dimer makes up the main body of the molecule, with each heavy chain containing a slightly elongated globular head at the amino terminus. The myosin globular heads are connected to a long $\alpha$-helical coiled tail of $\sim 120 \mathrm{kDa}$ that aggregates to form the rod-like backbone of the thick filament. Each myosin globular head contains the functional motor domains of the molecule which include the nucleotide and actin-binding regions. A single essential and regulatory light chain are associated with each myosin head. The light chains are localized along an $\alpha$-helical segment of the heavy chain at the junction of the globular head and the rod-like backbone; this portion of the $\alpha$ helical rod is frequently referred to as the "neck" region.

Myosin is believed to generate force and/or motion by mechanical cycles during which the myosin head repetitively attaches to actin, undergoes a conformational change that results in a power stroke and then detaches [45]. The energy required for the mechanical power is generated by the enzymatic hydrolysis of adenosine triphosphate (ATP) by the globular myosin head. A structural hypothesis (the "lever arm hypothesis") has been proposed to explain the conversion of chemical energy into directed movement $[46,47]$. In this model, the binding of ATP to myosin while it is bound to actin is proposed to result in a series of conformational changes in the myosin globular head that reduces its affinity for actin and allows it to hydrolyze
ATP to adenosine diphosphate (ADP) and inorganic phosphate $(\mathrm{Pi})$. As the myosin rebinds to actin and releases the nucleotide, the conformational changes are reversed causing movement of the myosin relative to actin. The light-chain binding domain ("the neck region") pivots about a fulcrum near where the globular head and light chain binding domains abut one another, resulting in the displacement of actin relative to myosin. This mechanism is essentially the same for smooth muscle and skeletal muscle myosins [48]. In smooth muscle, the phosphorylation of a single serine residue (serine-19) in the N-terminus of the regulatory light chain is the switch for turning on actin-activated adenosine triphosphatase (ATPase) activity and contraction. In vitro, smooth muscle regulatory light chain phosphorylation increases actinactivated ATPase activity by 50-100-fold [49-51].

Myosin filament assembly. Smooth and nonmuscle myosins share a common feature in that the phosphorylation of the $20 \mathrm{kDa}$ regulatory light chain can regulate the assembly of monomeric myosin into filaments in vitro, a feature not shared by skeletal muscle myosin [52-61]. The region of the myosin molecule that regulates the assembly of monomeric myosin into filaments appears to be localized to the C-terminal of the rod [62]. In vitro, if the regulatory light chain of myosin filaments is not phosphorylated, the addition of magnesium $(\mathrm{Mg})$ ATP results in the disassembly of myosin filaments into a soluble monomeric conformation of myosin in which the heavy chain rod is bent into thirds $[55,56]$. Phosphorylation of the regulatory light chain results in the unfolding of the rod and the reassembly of the monomers into myosin filaments.

The role of phosphorylation of the myosin regulatory light chain in the process of myosin filament assembly and disassembly in smooth muscles in vivo is not completely settled. There is general agreement that dephosphorylated myosin remains in filamentous form in uncontracted smooth muscle; however the possibility remains that there is a pool of folded monomeric myosin molecules in vivo that is recruited to myosin filaments when the muscle is activated and phosphorylation of the regulatory myosin light chains occurs [63]. This could regulate an activationdependent modulation of myosin filament number or length. Evidence from light and electron microscopic studies have demonstrated that contraction increases thick filament density in some smooth muscles (rat anococcygeus smooth muscle) but not others (guinea pig taenia coli) [63-65]. However, Horowitz et al. [66] detected only trace amounts of monomeric myosin in both relaxed and contracted gizzard smooth muscle using monoclonal antibodies to specifically label monomeric myosin, and these investigators concluded that the assembly/disassembly of myosin is unlikely to play a significant role in the contraction/relaxation cycle in gizzard smooth muscle. Although the available evidence does not support extensive assembly and disassembly of myosin filaments during the contraction/relaxation cycle in smooth muscle tissues; it does not rule out the possibility that increases in the number or length of existing myosin filaments may occur during contractile activation.

There are significant differences in the structure of myosin filaments in smooth muscle and skeletal muscle tissues. Electron microscopic evidence for myosin filament structure in vivo indicates a nonhelical side-polar arrangement 
of crossbridges along a rod-like myosin filament, with no central bare zone [67-69]. The crossbridges on smooth muscle myosin filaments project in opposite directions on opposite sides of the filament, such that the myosin rod heads along each side have the same polarity along the entire length of the filament $[68,69]$. This contrasts with the bipolar arrangement of crossbridges in skeletal muscle, where helically arranged crossbridges of opposite polarity project from each side of a central bare zone.

\section{The thin filaments of airway smooth muscle cells}

Structure and function of filamentous actin. Actin is the primary protein constituent of the thin filament and filamentous actin (F-actin) forms the thin filament backbone. A number of actin-binding proteins are bound to actin in the thin filaments; among these are tropomyosin, caldesmon, and calponin. Additional proteins that may also be tightly bound to actin filaments include filamin (also called actin binding protein (ABP) [70], the calponin-like protein SM22 [71, 72], myosin light chain kinase [73], and heat shock protein $27[74,75]$.

$\mathrm{F}$-actin is a polymeric protein composed of asymmetric bi-lobed $42 \mathrm{kDa}$ actin monomers. Each actin monomer consists of two major domains, "inner" and "outer", that are unequal in size [76-78]. In filamentous actin, the actin monomers form a double-stranded helical array in which the two strands cross every $36 \mathrm{~nm}[76,77]$. Four different isoforms of actin have been identified in the smooth muscle tissues of warm-blooded vertebrates: $\alpha$ - and $\gamma-$ "contractile " actin, and $\beta$ - and $\gamma-"$ cytoskeletal" actin [79]. The $\alpha$ - and $\gamma$-"contractile" actin, as well as $\gamma$ - and $\beta$ "cytoskeletal" actin isoforms have been identified in airway smooth muscle cells $[80,81]$. There is evidence that different actin isoforms are localized to different functional domains of the smooth muscle cell [39, 40, 82]. Differences in the N-terminal sequence of different actin isoforms may specialize subsets of actin to different functions by directing their binding to different actinbinding proteins.

Actin filament polymerization and organization. As in most eukaryotic cells, the polymer state of actin in smooth muscle is dynamic. Actin polymerizes at the filament ends and subunit exchange occurs even after a steady state is achieved in which net polymerization ceases [83]. Actin filament lengths are precisely determined and maintained by capping proteins such as tropomodulin and CapZ; these proteins are also known to be present in smooth muscle $[83,84]$. In many cell types, agonists can regulate the polymer state of actin through the activation and inhibition of proteins that nucleate, cap, or sever actin filaments [85]. Smooth muscle contains large amounts of gelsolin and profilin, both of which are potent regulators of actin filament polymerization [86, 87]. In canine tracheal smooth muscle, globular $(\mathrm{G})$-actin constitutes $\sim 40 \%$ of the total actin content [88]. After contractile stimulation, the G-actin content decreases by $30-40 \%$, suggesting that the contractile activation of tracheal muscle stimulates the polymerization of G-actin into F-actin.

Both smooth and skeletal muscle actin filaments are saturated with tropomyosin [89]. Individual tropomyosin molecules bind in an end-to-end fashion to form a continuous strand on the thin filament that lies along the double helix formed by the actin monomers [76, 90-92]. In striated muscles, the calcium $\left(\mathrm{Ca}^{2+}\right)$-sensitive troponin complex modulates the position of tropomyosin along the actin filament to regulate myosin binding to actin and consequently the activation and inactivation of actomyosin ATPase activity [93]. The function of tropomyosin in smooth muscle is less clear. As the thin filaments of smooth muscle lack troponin, the troponin-tropomyosin mechanism that regulates the actomyosin interaction in skeletal muscle cannot be operative.

Caldesmon (h-caldesmon, MW $150 \mathrm{kDa}$ ) is found on the thin filament beside tropomyosin, arranged continuously along the axis of the actin double helix [82, 94, 95]. In the presence of tropomyosin, caldesmon can inhibit actomyosin ATPase activity at the low ratios of caldesmon to actin likely to occur in vivo $(1: 14)$ [96]. The inhibition of actomyosin ATPase activity by caldesmon is reversed by its phosphorylation [97]. In airway smooth muscle, caldesmon undergoes phosphorylation in response to contractile activation; this has led to the suggestion that it may play a role in the regulation of contraction in this tissue [97, 98]. The affinity of caldesmon for actin is greatly attenuated by $\mathrm{Ca}^{2+}$-calmodulin $[96,99-101]$. Thus, it has been proposed that caldesmon may interact with tropomyosin to modulate actomyosin ATPase activity in smooth muscle in a manner somewhat analogous to that of troponin in skeletal muscle [99, 102-104].

Calponin is a $34-\mathrm{kDa} \mathrm{Ca}^{2+}$-calmodulin binding protein that is also distributed with actin filaments in smooth muscle cells in vivo $[41,105]$. The function of calponin and its structural relationship to other proteins on the actin filament is currently unclear. Like caldesmon, calponin inhibits actin-activated myosin MgATPase activity in vitro $[106,107]$, and also inhibits actin filament movement in vitro motility assays $[108,109]$. There is considerable controversy over whether calponin and caldesmon interact on the same filament in vivo. Ultrastructural evidence suggests that calponin and caldesmon localize to different actin filaments or different locations on the same filament $[41,110]$.

Functional specialization of thin filaments in smooth muscle. SMALL and coworkers $[39,111]$ first distinguished two distinct subsets of actin filaments that localized to different physical domains within the smooth muscle cell. "Cytoskeletal" $\beta$-actin was selectively localized to the dense bodies, the membrane-associated dense plaques, and to the longitudinal channels linking consecutive dense bodies. These areas were also occupied by the actin-binding proteins filamin and desmin, the major constituent of intermediate filaments [16, 40, 111]. "Contractile" $(\alpha-$ or $\gamma-)$ actin was associated with myosin filaments in complementary positions to those occupied by "cytoskeletal" actin [40].

There is evidence that actin-binding proteins associate selectively with different actin isoforms and localize to different functional domains within smooth muscle cells. Ultrastructural evidence from a number of different laboratories supports the preferential distribution of caldesmon to actin filaments that are associated with myosin (the contractile domain) $[41,42,82,112]$. However, the results of studies describing the cellular localization of calponin 
are less consistent. Whereas WALSH et al. [105] found that calponin was homogeneously distributed with actin and tropomyosin throughout toad stomach and chicken gizzard smooth muscle cells, NORTH et al. [41] concluded that calponin was more concentrated in regions of "cytoskeletal" $\beta$-actin. NorTH et al. [41] also observed calponin in cytoplasmic dense bodies and at the adhesion plaques at the cell surface. MABUCHI et al. [42] observed calponin to be distributed primarily at the periphery of cytoskeletal structures in the same general region as desmin, and very often adjacent to $\beta$-actin. In these studies, the distribution of calponin bore no similarity to that of caldesmon and myosin. MABUCHI et al. [43] suggested that calponin functions as a bridging protein between actin and intermediate filament networks at dense bodies. Ultrastructural data by HodGKInson et al. [113] indicates that the location of calponin on F-actin is similar to that of the actin crosslinking protein fimbrin, as well as to that of $\alpha$-actinin and gelsolin. They suggested that calponin may function to competitively inhibit the binding of these or other actinbinding proteins to the actin filament. Thus calponin could regulate remodelling of the actin cytoskeleton and thereby affect the mechanical response of the smooth muscle cell.

\section{Molecular basis for the mechanical properties of tracheal smooth muscle}

\section{Regulation of active tension and shortening in airway smooth muscle}

Role of myosin light chain phosphorylation. In smooth muscle, the $\mathrm{Ca}^{2+}$-dependent phosphorylation of myosin light chain (MLC) 20 is a prerequisite to the initiation of crossbridge cycling and force development or active shortening. In tracheal smooth muscle, as well as in other smooth muscles, force development is preceded by a rapid increase in the phosphorylation of MLC 20 and intracellular $\mathrm{Ca}^{2+}[114-116]$. In neurally stimulated tracheal smooth muscle, maximum rates of shortening and MLC phosphorylation can be attained after $5 \mathrm{~s}$ of stimulation $[114,115]$. Under these stimulation conditions, transient increases in both shortening velocity and MLC phosphorylation precede the development of maximal active force. The stiffness of the muscle increases in parallel with the increase in MLC 20 phosphorylation prior to the development of active tension. This increase in stiffness has been attributed to the attachment of crossbridges that precedes force development.

There is a wealth of data from both intact and skinned smooth muscle tissues correlating the initiation of force development with increases in MLC phosphorylation [116-119]; however the correlation between force and MLC phosphorylation is not simple. In carotid arterial smooth muscle, DiLlon et al. [120] found that after an initial transient increase in shortening velocity and MLC phosphorylation, force remained elevated while shortening velocity and MLC phosphorylation declined. The observation that the decline in MLC phosphorylation was coincident with the decline in shortening velocity led these investigators to hypothesize that active tension and shortening velocity can be independently regulated based on the phosphorylation state of MLC 20. They proposed that the rate of shortening was regulated by the proportion of phosphorylated crossbridges, whereas active tension was proposed to be maintained by attached crossbridges that had been dephosphorylated. These crossbridges, termed "latchbridges" were hypothesized to cycle much more slowly than phosphorylated crossbridges. The latchbridge hypothesis was subsequently formalized in a model [121-124] in which $\mathrm{Ca}^{2+}$-dependent MLC phosphorylation was both necessary and sufficient for the development of the "latch" state. The central assumption of the model is that crossbridges can exist in four states: detached-phosphorylated, attached-phosphorylated, detached-dephosphorylated, and attached-dephosphorylated. According to this model, both phosphorylated and dephosphorylated attached crossbridges are capable of sustaining force, but only phosphorylated crossbridges are capable of forming attachments. The dephosphorylatedattached crossbridges have a very slow rate of detachment, thus limiting the crossbridge cycling rate and the rate of shortening.

Data supporting the application of the latchbridge hypothesis to airway smooth muscle has been equivocal, mainly because in this tissue MLC phosphorylation and shortening velocity are not closely correlated under many conditions of stimulation. A transient increase in MLC phosphorylation is observed in association with a transient increase in shortening velocity during the maximal activation of rabbit trachealis muscle by muscarinic stimuli $[115,125]$; however, under many other conditions of stimulation, this correlation breaks down. Canine trachealis muscle activated by potassium $\left(\mathrm{K}^{+}\right)$-depolarization exhibits a decline in shortening velocity during the course of the contraction while high levels of active tension and myosin light chain phosphorylation are sustained [126, 127]. A similar dissociation between shortening velocity and MLC phosphorylation is observed when trachealis muscles are activated with submaximal concentrations of muscarinic agonists or with agonists of lower efficacy, such as 5-hydroxytryptamine [126, 128]. It is therefore unclear whether the decline in shortening velocity that occurs in airway muscle during a sustained contraction can be attributed to the dephosphorylation of attached crossbridges (latchbridges). In addition, $\mathrm{Ca}^{2+}$-depleted trachealis muscle that is stimulated with muscarinic agonists exhibits high levels of MLC phosphorylation in the absence of significant tension development or active shortening [129, 130].

Regulation of force and shortening velocity by second messengers. The relationship between intracellular $\mathrm{Ca}^{2+}$, MLC phosphorylation, and active stress can be modulated by conditions of contractile stimulation. Tracheal muscles contracted to comparable levels of active tension by $\mathrm{K}^{+}$depolarization and by carbachol exhibit lower levels of MLC phosphorylation during the contractions induced by $\mathrm{K}^{+}$-depolarization [130]. Isoproterenol-induced relaxation of tracheal smooth muscles contracted by $\mathrm{K}^{+}$-depolarization is not associated with a decrease in intracellular $\mathrm{Ca}^{2+}$ or a decline in MLC phosphorylation [131, 132]; whereas tracheal muscles that are stimulated to relax with isoproterenol after contraction with muscarinic agonists exhibit a decline in both intracellular $\mathrm{Ca}^{2+}$ and MLC phosphorylation. 
The mechanisms by which pharmacological agonists modulate the relationships between intracellular $\mathrm{Ca}^{2+}$, MLC phosphorylation, force and shortening velocity have not been fully established. STULL and coworkers [131, 133, 134] demonstrated that $\mathrm{Ca}^{2+}$-calmodulin dependent protein kinase II phosphorylates MLC kinase in tracheal smooth muscle and that this inhibits MLC kinase activity, thereby decreasing the $\mathrm{Ca}^{2+}$-sensitivity of MLC phosphorylation. Thus, the $\mathrm{Ca}^{2+}$-dependent phosphorylation of MLC kinase may contribute to differences in the relationship between tension and MLC phosphorylation observed when muscles are activated by different agonists [131, 133-135]. However, the sensitivity of MLC kinase to activation by $\mathrm{Ca}^{2+}$ calmodulin remains unchanged during the relaxation of bovine tracheal muscle by isoproterenol $[131,136]$. Thus differences in the $\mathrm{Ca}^{2+}$ sensitivity of MLC phosphorylation during relaxation with isoproterenol are unlikely to be mediated by effects on the $\mathrm{Ca}^{2+}$-sensitivity of MLC kinase.

The small guanosine triphosphatase (GTPase) rho may contribute to the regulation of MLC phosphorylation in airway smooth muscle. In permeabilized tracheal smooth muscle strips, acetylcholine stimulates MLC phosphorylation and force development when the intracellular $\mathrm{Ca}^{2+}$ concentration is maintained at a constant level [137-139]. The increases in MLC phosphorylation and tension in these tissues can be blocked by $\mathrm{C} 3$ exoenzyme, which specifically inhibits the activation of rho $[137,138]$. The mechanism by which rho modulates tension development in airway smooth muscle has not been determined; however, in cultured cells, rho activates rho kinase, which can phosphorylate the myosin binding subunit of MLC phosphatase, thus decreasing phosphatase activity and increasing MLC phosphorylation [140, 141]. In vitro, rho kinase can also directly phosphorylate MLC 20 [142].

Cytoskeletal and actin binding proteins have also been proposed to play a role in regulating the relationship between MLC phosphorylation and active shortening in airway smooth muscle. Caldesmon inhibits actomyosin ATPase activity and actin filament sliding velocity in vitro $[97,143]$, and the phosphorylation of caldesmon by mitogen-activated protein (MAP) kinase in vitro reverses this inhibition [97, 98]. Caldesmon undergoes phosphorylation during the contractile activation of tracheal smooth muscle [144]; thus this could provide a thin-filament mediated mechanism for the regulation of actomyosin ATPase activity that would operate independently of MLC phosphorylation. Calponin has also been found to inhibit actomyosin ATPase activity and actin sliding velocity in vitro [97, 145], and the inhibition of actomyosin ATPase activity by calponin can be reversed by phosphorylation $[106,145,146]$. Contractile activation with carbachol induces a transient increase in calponin phosphorylation in tracheal smooth muscle [97, 145]. Thus, like caldesmon, calponin might contribute to the regulation of crossbridge cycling in airway smooth muscle by a mechanism that is separate and independent of MLC phosphorylation.

The contractile activation of tracheal smooth muscle also increases the tyrosine phosphorylation of a number of integrin-associated cytoskeletal proteins, including focal adhesion kinase (FAK) and paxillin [147, 148]. However, the functional role of these proteins in the contraction of smooth muscle has not yet been established. Tyrosine phosphorylated proteins have been proposed to play a role in the $\mathrm{Ca}^{2+}$-sensitization of agonist-induced contraction in other smooth muscle tissues $[149,150]$. In nonmuscle cells, FAK contributes to the regulation of cell motility and cell spreading [151-154].

Increased levels of MLC phosphorylation may contribute to the increase in responsiveness of airway smooth muscle that occurs with inflammation or after allergic sensitization $[155,156]$. Ragweed-sensitized canine tracheal smooth muscle exhibits higher shortening velocities that are associated with elevated levels of MLC phosphorylation and increased activity of MLC kinase [157]. However, the mechanisms by which allergic sensitization might increase MLC kinase activity have not been established.

Mechanism for the length-dependence of active force in airway smooth muscle

Role of length-tension properties in the regulation of airway smooth muscle contractility. Tracheal smooth muscle exhibits a relatively broad length-tension relationship in which high levels of active force can be elicited over a comparatively wide range of muscle lengths, and active isometric force is observed at lengths as short as $20 \%$ of the optimal length (Lo) [158-160]. The length-tension properties of bronchial muscle are similar, although the relationship between length and isometric tension is somewhat steeper for large bronchi than for small bronchi [160].

The length-tension properties of airway smooth muscle play an important role in determining the contractility of the intact airway. In canine airways, maximal active tension occurs at $\sim 80 \%$ of maximum airway volume in both large and small bronchi, as well as in the trachea [160, 161]. As a result of differences in the effects of airway geometry on active pressure, tension, and stress in a cylindrical organ such as a bronchus, the curve for relationship between airway volume (or circumference) and active pressure is much flatter than that between airway volume and active tension or active stress (fig. 1). Although the relationship between muscle length and active stress in small muscular bronchi is qualitatively similar to that for trachealis muscle strips, this translates into relatively constant levels of active pressure generation over most of the physiological range of bronchial volume. Small changes in the slope of the relationship between muscle length and active stress can translate into large differences in the pressure generated by the intact airway at lower volumes. As in other smooth muscles, the slope of the length-tension curve in airway smooth muscle is steeper at submaximal levels of agonist stimulation and for weaker agonists than during maximal stimulation $[3$, $162,163]$. Thus, the effect of an increase in stimulus intensity on airway smooth muscle contractility is amplified at suboptimal muscle lengths. Because the intact airway operates physiologically well below the Lo; measurements of isometric force at Lo can markedly underestimate the impact of different stimulation conditions on airway contractility in vivo.

Molecular basis for the length-tension relationship in airway smooth muscle. The molecular mechanisms underlying the length-tension properties of smooth muscle are 

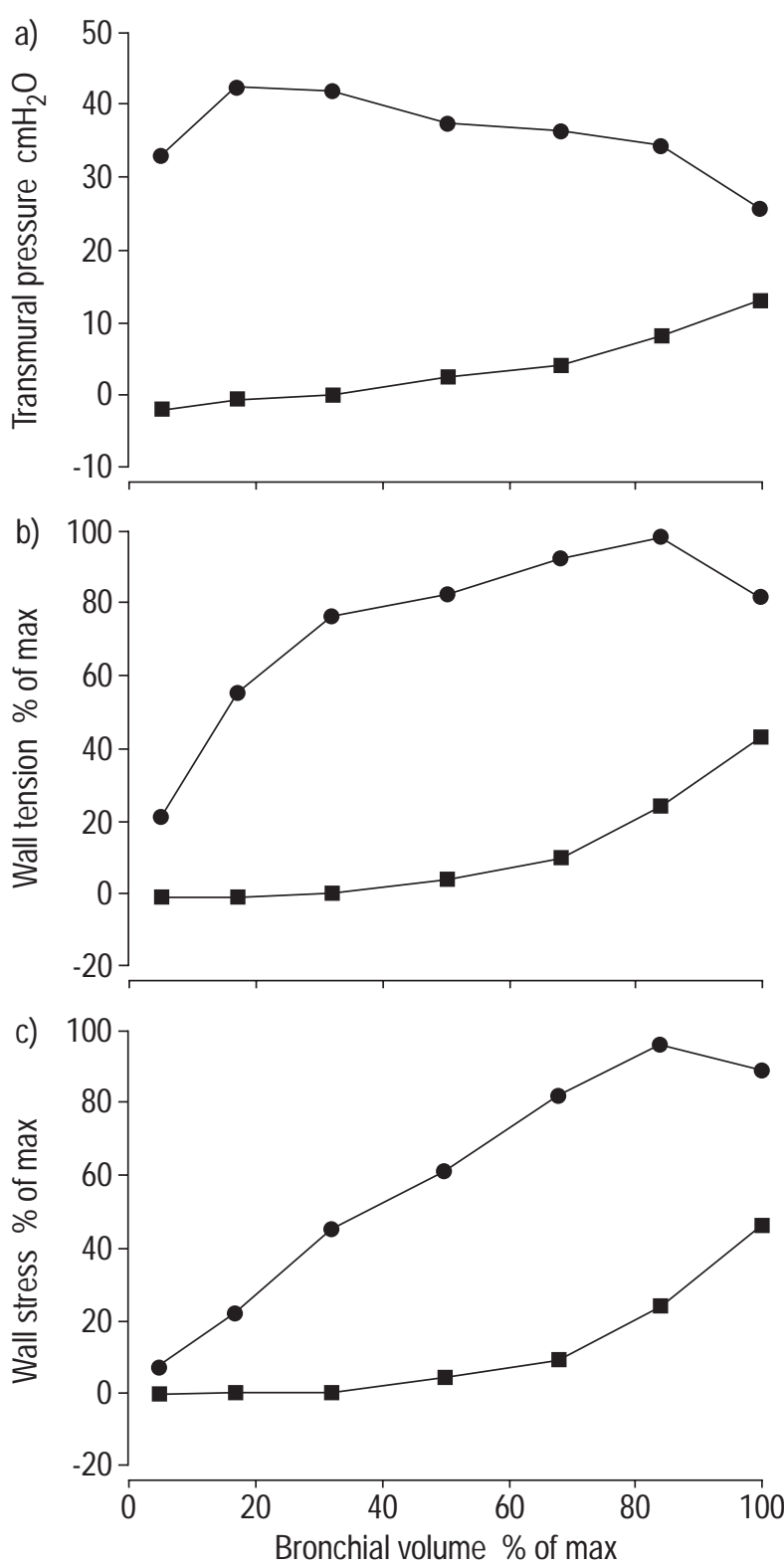

Fig. 1. - Active pressure tension and circumferential tension and circumferential stress in an isolated muscular bronchi at different bronchial volumes before and after active contraction with acetylcholine at constant volume. Values shown represent mean values obtained on seven bronchi. Transmural pressure (a) was measured in each airway before and after contraction at each volume. Circumferential tension (b) and stress (c) were calculated from measurements of pressure. active; $\boldsymbol{\square}$ : passive. Modified from Ref. [160].

still not established. In skeletal muscle, the structure of the sarcomere unit has been fundamental to the interpretation of the mechanistic basis for the relationship between muscle length and isometric tension. The length-tension behaviour of striated muscles has been interpreted in terms of changes in the overlap between the thick and thin filaments as proposed by GoRDON et al. [164]. In single skeletal muscle fibres, maximal active isometric tension is observed when the crossbridge arrays of the thick filaments are fully overlapped by the thin filaments. When the fibre is stretched beyond its Lo, isometric force declines due to a reduction in the overlap of actin and myosin filaments with a consequent decrease in the number of crossbridges that can interact with actin. At fibre lengths shorter than the optimum length, the decline in active force is attributed to a decline in the interaction of actin with the myosin heads on thick filaments as the opposing thin filaments begin to overlap with the central bare zone on the thick filaments and with each other. At extremely short lengths, tension falls dramatically due to structural interference with contraction caused by myosin filaments abutting the Z-lines [164].

This mechanism is difficult to extrapolate to the smooth muscle cell, due to the significant differences in the structure of the contractile apparatus. As discussed in The thick filaments of airway smooth muscle section, most of the available evidence suggests that the thick filaments of smooth muscle are side-polar with crossbridges on each side of the filament maintaining the same polarity $[68,69]$. There is no central bare zone; instead bare zones are found at the ends of the thick filaments [6769]. Thus there is no clear structural basis for actin filaments of opposite polarity to abut each other at short muscle lengths or for them to overlap in a central bare zone. These structural differences make it difficult to account for the length-tension properties of smooth muscle on the basis of changes in filament overlap. This is particularly true for the ascending limb of the lengthtension curve, the physiological range of length for most smooth muscle tissues and for airway smooth muscle. Although changes in the overlap of actin and myosin filaments in smooth muscle may contribute to its lengthtension properties, there is currently no structural evidence that supports a mechanistic model as to how this might occur.

A number of other mechanisms have been proposed to contribute to the length-dependence of tension in smooth muscle tissues. These include mechanical interactions between adjacent cells, length-dependent changes in the activation of contractile filaments, and mechanosensitive alterations in the organization or length of the contractile filaments. The mechanical interactions between neighbouring cells may be an important factor limiting the shortening and force development of airway smooth muscle at short muscle lengths [165-167]. Airway smooth muscle tissues that are subjected to mild digestion of extracellular connective tissue with collagenase shorten more and develop more force at short lengths than untreated tissues [167, 168]. Force transmission across the sarcolemma of smooth muscle cells to the ECM and to neighbouring smooth muscle cells occurs at membrane-associated dense plaques. As the neighbouring cells of smooth muscle tissues are mechanically coupled, the contractile apparatus of each individual cell exerts tension on its neighbours, and this tension acts as a load to limit shortening. In contrast to intact smooth muscle tissues, single smooth muscle cells develop similar levels of maximal isometric force when contractions are initiated over a wide range of cell lengths [169]. This observation also suggests that a significant portion of the length-dependence of tension in smooth muscle results from intercellular mechanical interactions.

Some of the length-dependence of isometric force in smooth muscle may be due to length-dependent changes in the activation of contractile proteins [170-172]. In both tracheal and arterial smooth muscle tissues, the lower 
levels of force associated with the isometric contraction of muscles at lengths below the Lo, are associated with lower levels of $\mathrm{Ca}^{2+}$ activation and MLC phosphorylation [170-174]. This suggests that mechanosensitive processes may modulate the signalling pathways that regulate the activation of contractile proteins. In tracheal muscle, there is evidence that a mechanosensitive pathway mediated by the cytoskeletal proteins FAK and paxillin may provide a pathway for the mechanosensitive modulation of contractile protein phosphorylation [148].

Modulation of the organization of the contractile filaments within smooth muscle cells may also contribute to the length-tension properties of airway smooth muscle. In nonmuscle cells, changes in cell shape or stiffness in response to mechanical stimuli are mediated by remodelling of the actin cytoskeleton [36, 37]. This may occur by remodelling of the length of actin filaments, and/or through changes in the sites of actin filament attachment to the smooth muscle membrane. The contractile activation of trachealis muscle strips with acetylcholine decreases the content of soluble monomeric G-actin by $30-40 \%$ [88]. In addition, latrunculin A or cytochalasin $\mathrm{D}$, which inhibit actin polymerization, profoundly inhibit force development in tracheal muscle [88, 175]. The inhibition of force by latrunculin is not associated with any effects on MLC phosphorylation, suggesting that its effects on force result directly from its effects on actin polymerization [88]. These observations suggest that actin filament remodelling plays an important role in airway smooth muscle contraction. Furthermore, the length-tension curve of tracheal smooth muscles treated with latrunculin $\mathrm{A}$ is much flatter than for untreated tissues, suggesting that actin filament remodelling may contribute significantly to the length-tension properties of airway smooth muscle [88].

The contractile activation of tracheal smooth muscle stimulates the phosphorylation of paxillin and FAK, and the degree of phosphorylation of these proteins is sensitive to muscle length $[147,148,176]$. The stimulation of $\mathrm{Ca}^{2+}$ depleted tracheal smooth muscle strips with acetylcholine also elicits an increase in the tyrosine phosphorylation of both paxillin and FAK that occurs without an increase in MLC phosphorylation or force development [177]. The length-sensitivity of paxillin and FAK phosphorylation is retained in $\mathrm{Ca}^{2+}$-depleted tissues, suggesting that these proteins may be upstream mediators of mechanosensitive events in airway smooth muscle [148]. In nonmuscle cells, mechanical strain is sensed by transmembrane integrins and transduced by integrin-associated cytoskeletal proteins into signalling pathways that regulate cytoskeletal remodelling and other strain-sensitive cellular processes [148, 178-181]. Thus the mechanosensitive signalling pathway in tracheal muscle may be analogous to the integrin-mediated pathway demonstrated in nonmuscle cells, and it may provide a mechanosensitive pathway for the regulation of actin filament organization and contractile protein activation.

Alterations in the length or number of myosin filaments have also been proposed to play a role in regulating the length-tension properties of tracheal smooth muscle. PRATUSEVICH et al. [182] proposed that the phosphorylation of MLCs stimulated by contractile activation initiates the polymerization of myosin filaments. Myosin filaments may lengthen to adapt to contractile activation at longer muscle lengths or new myosin filaments may be formed. This could result in a series to parallel shift in the organization of the contractile apparatus. There is ultrastructural evidence that the number of myosin filaments increases modestly during the contraction of some smooth muscle tissue types, but not in others (see The thick filaments of airway smooth muscle section); however the effect of contraction on myosin filament density has not been investigated in airway smooth muscle. If actin filaments undergo reorganization upon contractile activation, the myosin filaments associated with this actin might also undergo rearrangement in order to optimize force production $[182,183]$. However, there is currently no direct evidence for the polymerization of myosin in association with the contraction of airway smooth muscle.

Plasticity of the length-tension properties of airway smooth muscle. The length-tension relationship of trachealis muscle cannot be represented by a single function for a given set of stimulation conditions; the tension generated by the muscle at a particular muscle length varies depending on the contraction history of the muscle $[3,163,170$, 182] (fig. 2). When the length of an actively contracting trachealis muscle is decreased during the contraction, force redevelopment at the shorter length is lower than when the contraction is initiated at that length $[163,170$, 184] (fig. 2a-f). The depression of force redevelopment at the shorter length is proportional to the size of the length step [163]. Similarly, force development at any muscle length is lower when the muscle shortens to that length isotonically, than when it is contracted at that length under isometric conditions [3]. This property cannot be attributed to a deactivation of contractile proteins induced by shortening, because MLC phosphorylation is not depressed in association with the depression of force caused by changes in muscle length [170] (fig. $2 \mathrm{~g}$ and $\mathrm{h}$ ). Furthermore, force during isometric contraction is also depressed if the length of the muscle is decreased immediately prior to contractile activation.

The plasticity of the mechanical response of tracheal smooth muscle is also evident with respect to other functional properties of the muscle. When muscle strips are subjected to isotonic shortening manoeuvres initiated during isometric contraction, the shortening velocity measured at any muscle length depends on its length history [159]. The rate of active shortening measured at a particular muscle length is higher when isotonic shortening is initiated after isometric contraction at a short length than when the isotonic shortening is initiated after isometric contraction at a long muscle length under otherwise identical conditions [159].

These observations and similar observations in other smooth muscle tissues have led to the hypothesis that airway smooth muscle cells can modulate the organization of their contractile apparatus to accommodate to changes in their physical environment [159, 166, 169, 182, 185]. According to this proposal, contraction of the muscle at a short muscle length results in the rearrangement of contractile filaments into a shorter thicker array to accommodate to the short, thick shape of the smooth muscle cell $[182$, 185] (fig. 3). Contraction of the muscle at a long length results in the rearrangement of the contractile filaments into a longer thinner array. When the muscle is contracted at a long muscle length and then shortened 

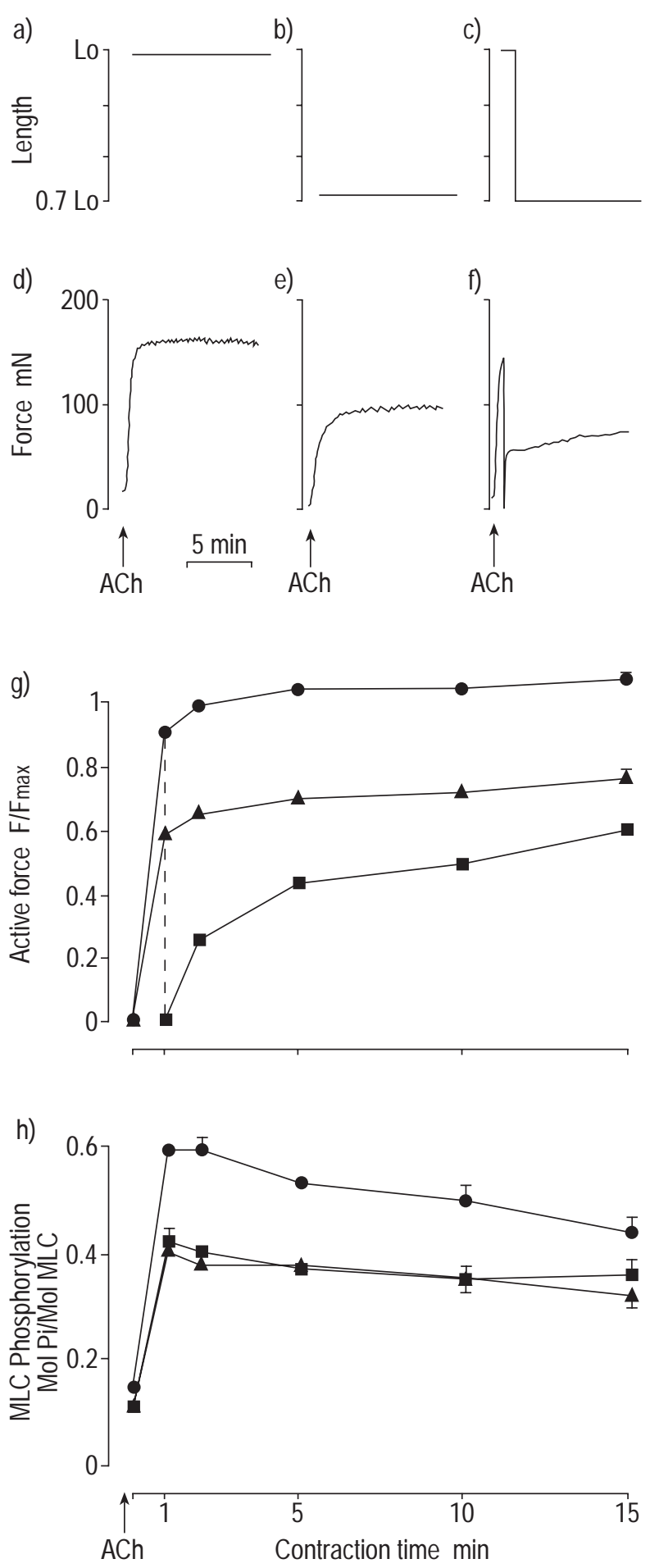

Fig. 2. - a) Experimental protocol. Muscles were contracted isometrically at a) and d) optimal length (Lo) or b) and e) 0.7 Lo, or c) and f) the contraction was initiated at Lo and muscle length was decreased to 0.7 Lo after $1 \mathrm{~min}$. Shortening the muscle after the initiation of contraction resulted in a depression of force redevelopment at the shorter length. g) Active force and h) myosin light chain (MLC) phosphorylation at Lo and at 0.7 Lo during isometric contraction or following a step decrease in muscle length. Shortening the muscle after 1 min resulted in a significant depression of force redevelopment that was not associated with a corresponding depression of MLC phosphorylation. Values shown are means from 10-14 muscles. Modified from Ref. [170]. g) $\bigcirc$ : Lo; $\boldsymbol{\Delta}: 0.7$ Lo; : Lo to 0.7 Lo. h) : Lo; $\boldsymbol{\Delta}: 0.7 \mathrm{Lo}$; : Lo to $0.7 \mathrm{Lo}$ : ACh: acetylcholine; F/Fmax: active force normalized to maximal active force; $\mathrm{Pi}$ inorganic phosphate. a)

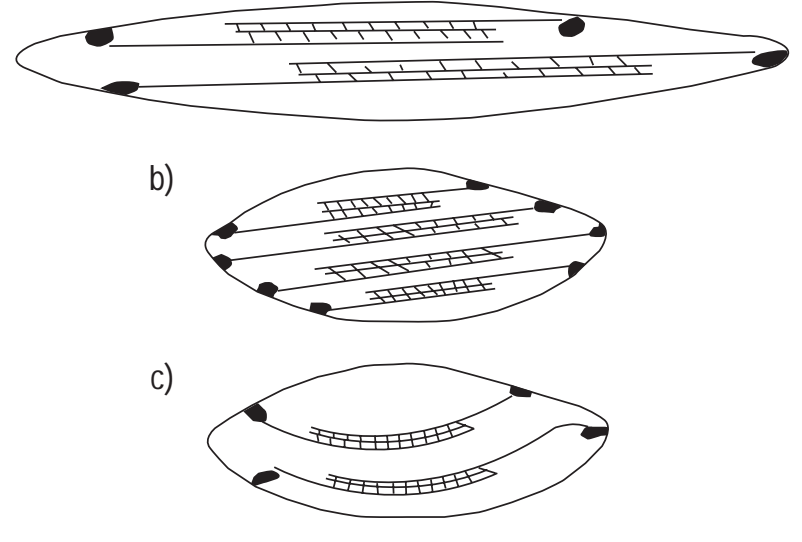

Fig. 3. - Hypothetical scheme for reorganization of the contractile apparatus of the airway smooth muscle cell. The organization of the contractile apparatus adapts to the shape of the smooth muscle cell when the cell is actively contracted at different muscle lengths. Contractile filament organization becomes relatively fixed after full activation of the muscle is achieved. When the length of the fully activated muscle is decreased abruptly, the organization of the contractile apparatus cannot adapt to the new length and muscle contractility is depressed. a) Contraction at long length; b) contraction at short length; c) decrease from long to short length during contraction.

while it is activated, the contractile apparatus is unable to reorganize to adapt to the change in length. This results in a depression of contractility (fig. 3).

Mechanical properties of airway smooth muscle under dynamic conditions

Mechanical modulation of airway smooth muscle tone in vivo. The smooth muscle of the airways is unique among smooth muscle tissues in that it is continually subjected to changes in length and load due to stretch and retraction of the airways during breathing. The physiological effects of lung volume changes on airway tone are well-documented. In healthy human subjects, deep inspiration decreases airway resistance and increases expiratory flow [186-189]. The stretch and retraction of the airways that occurs during normal tidal breathing has also been shown to have a significant modulatory effect on airway tone in experimental animals: the increase in airway resistance in response to bronchial challenge is significantly lower during tidal breathing than under static conditions in both dogs and rabbits $[190,191]$. This data suggests that the effects of stretch and mechanical oscillation on airway smooth muscle may be important in maintaining normal low levels of airway reactivity. Several laboratories have demonstrated that the inhibition of deep inspiration in healthy nonallergic subjects results in airway hyperreactivity that is similar in degree to that observed in asthmatic subjects $[192,194]$. Such observations have led to the proposal that stretch of the airways caused by tidal breathing or deep inspiration may be reduced in asthmatic subjects, and that this may result in the airway hyperreactivity characteristic of asthma [195].

The effects of lung volume history on airway tone in vivo can be mimicked in isolated bronchial segments in vitro [196]. In these segments, inflation-deflation cycles decrease the transmural pressure of contracted bronchi well below the pressure obtained under static conditions 
(fig. 4). The effect of mechanical oscillation on the contractile force of isolated strips of tracheal and bronchial smooth muscle are similar to those observed in isolated bronchial segments: length oscillation decreases the active force of a contracted muscle strip below that obtained under static conditions [197-199]. This suggests that the effects of mechanical oscillation on airway responsiveness result directly from the effects of oscillation on the airway smooth muscle.

Tracheal smooth muscle exhibits a characteristic pattern of behaviour during imposed cycles of length oscillation [197-199] (fig. 5). When the length of contracted trachealis muscle strips is oscillated, force decreases markedly below the isometric force during the shortening phase of the length-oscillation cycle, and remains below the static force during the lengthening phase of the cycle until the muscle is stretched back to the peak cycle length. Thus, the active force of the muscle is significantly depressed during the oscillation over most of the range of the length cycle. The effect of oscillation on force occurs even at extremely low frequencies of length oscillation, 1 cycle $\cdot \mathrm{min}^{-1}$ or slower $[197,198]$. The degree of depression of force during length oscillation is directly correlated with both the frequency and magnitude of the oscillation. When either the frequency or amplitude of the length oscillation is increased, force during the oscillation cycle decreases. Similarly, oscillations in distending force that are imposed on actively contracted tracheal smooth muscle cause the muscle to lengthen, and the degree of lengthening is directly correlated with the force fluctuation amplitude [200].

Multiple cellular mechanisms are likely to contribute to the effects of mechanical oscillation on airway smooth muscle: shortening and lengthening of passive elastic elements within the muscle cells and tissue; active shortening and lengthening of the contractile element (crossbridge detachment and reattachment); and remodelling of the cellular organization of the contractile apparatus. Len-

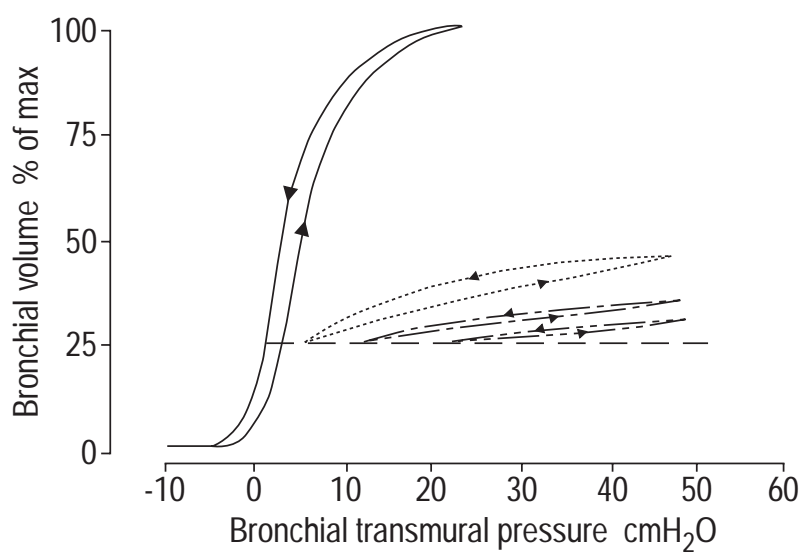

Fig. 4. - Effect of volume oscillation on the transmural pressure of an actively contracted isolated canine bronchial segment. When the bronchus is contracted with acetylcholine at constant volume, the transmural pressure reaches $50 \mathrm{cmH}_{2} \mathrm{O}$. The transmural pressure of the bronchus during volume oscillation is lower than the transmural pressure maintained at constant volume. The transmural pressure during volume oscillation decreases as the amplitude of the oscillation is increased. --- : no oscillation; - - - : contracted with acetylcholine (ACh) at an oscillation volume of $20 \%$; - - - : contracted with ACh at an oscillation volume of $10 \% ;--\ldots--$ : contracted with $\mathrm{ACh}$ at an oscillation volume of $5 \%$; $:$ : uncontracted.

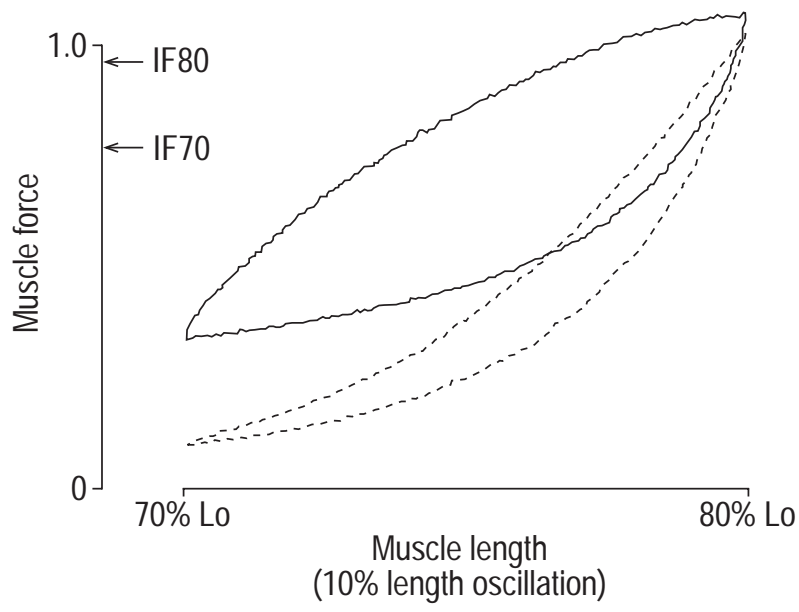

Fig. 5. - Effect of length oscillation on active force in a trachealis muscle strip activated with acetylcholine. Force was much lower during oscillation of the muscle strip over $10 \%$ of its length than during static isometric contraction regardless of the oscillation rate. However, decreasing the rate of oscillation increased the force during the length oscillation cycle. $\longrightarrow: 1.5$ cycles $\mathrm{min}^{-1} ;$ - - - : : 120 cycles $\cdot \mathrm{min}^{-1}$. Lo: optimal length; IF70: isometric force at $70 \%$ Lo; IF80: isometric force at $80 \%$ Lo.

gth changes that occur during the mechanical oscillation of smooth muscle undoubtedly cause the detachment of crossbridges, and this results in a decrease in active force $[198,200]$. The rate of length oscillation will affect the degree of crossbridge reattachment and thereby modulate the active force during the oscillation cycle. When the rate of the imposed length change is much faster than the active shortening velocity of the muscle, few detached crossbridges can reattach during the oscillation cycle. Under these conditions, shortening and lengthening of the muscle will result primarily in stretch and retraction of the viscoelastic components of the tissue and force during the oscillation cycle will therefore remain low. If the rate of length change is slower than the active shortening velocity of the muscle, new crossbridges will detach and reattach during each oscillation cycle. The slower the rate of cycling, the more attached crossbridges will be present at any time, resulting in higher overall levels of force during the oscillation cycle [197, 198]. FREDBERG et al. [200] have proposed that when the amplitude of stretch on the muscle during the oscillation is small, the number of attached dephosphorylated crossbridges (latchbridges) will increase and further decrease the rate of crossbridge detachment, thereby resulting in higher levels of muscle stiffness. The increased stiffness of the muscle then inhibits muscle stretch, thus leading to a self-reinforcing cycle.

However, crossbridge phenomena cannot account for many of the properties of airway smooth muscle observed during imposed length changes. As discussed in the Mechanism for the length-dependence of active force in airway smooth muscle section, the length-history dependent properties of airway smooth muscle are difficult to explain on the basis of crossbridge properties alone. Furthermore, when airway smooth muscle tissues are subjected to forced elongation, the relationship between force and muscle length shifts along the length axis in relation to the length at which active contraction of the muscle was initiated (fig. 6) [201]. The same trachealis muscle strip is stiffer and 

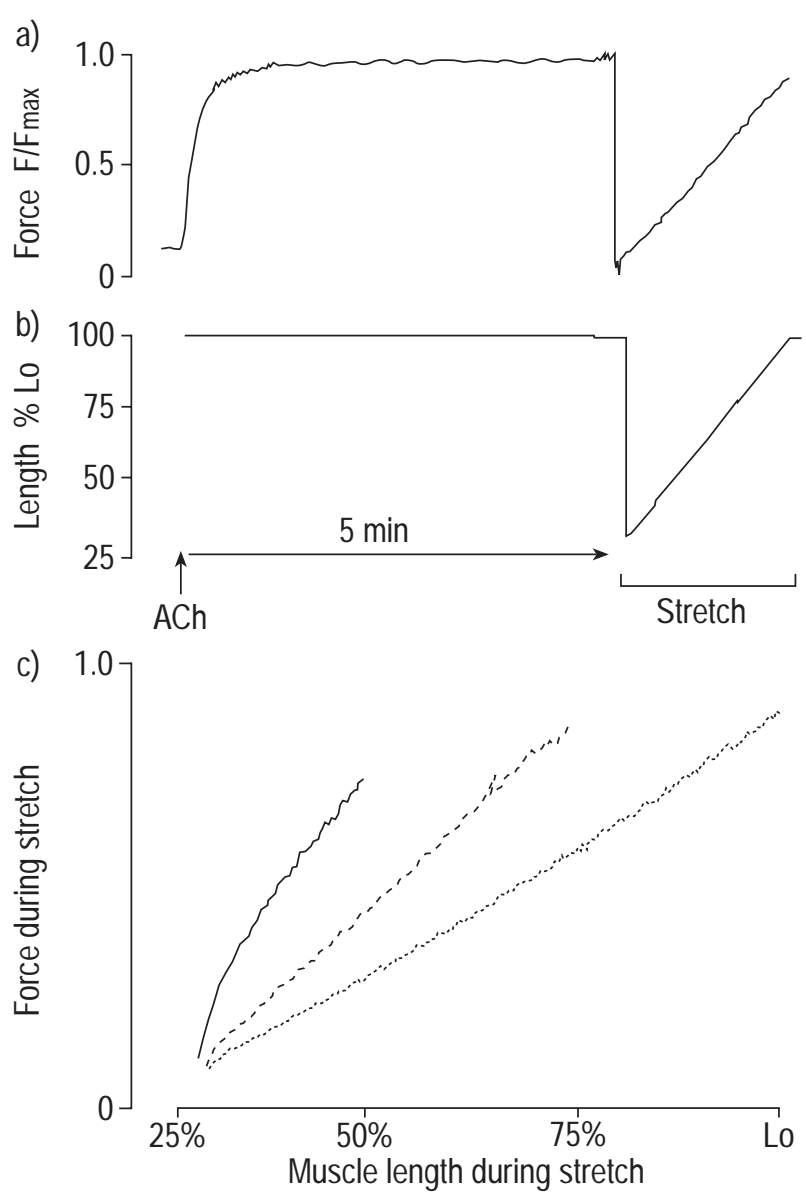

Fig. 6. - Plasticity of stiffness of tracheal smooth muscle tissue. a) and b) Experimental Protocol. Trachealis muscle strip was contracted isometrically at different starting lengths (optimal length (Lo) illustrated) in successive contractions, and then rapidly shortened to 0.25 Lo and slowly stretched back to the starting length while still activated. c) Muscle length and force during the stretch were plotted against each other as an index of muscle stiffness. The position of the force-length curve is displaced along the length axis in relation to the starting length, indicating that the muscle is stiffer after contraction at a short length than after contraction at a long length. —— : $50 \% \mathrm{Lo} ;-\ldots$ - : $75 \% \mathrm{Lo} ; \ldots \ldots \ldots . .$. Lo. F/Fmax: active force normalized to maximal active force. ACh: acetylcholine.

more difficult to stretch when it is shortened and re-extended after isometric contraction is initiated at a short length than when it is re-extended after isometric contraction with the same stimulus at a long length. This is consistent with the hypothesis that the structure of the actin filament lattice that provides the skeletal framework for myosin filament sliding is modulated in response to the external strain to which the muscle is subjected. According to this hypothesis, the cytoskeletal lattice organization becomes "fixed" rapidly upon the activation of the muscle, and can be modified relatively slowly after full activation of the muscle has been achieved. Active shortening of the muscle is mediated by the sliding of myosin filaments over the actin filament lattice. The observation of parallel shifts in the re-extension curves of the tracheal muscle following activation at different lengths is consistent with a mechanism in which contractile element length and muscle length are determined independently.
Under the dynamic conditions present during length oscillation, the cytoskeletal lattice structure would be forced to adapt to the conformation of the muscle cell at the maximum length to which the muscle was stretched during the length oscillation cycle. When stretch of the muscle was minimal and the muscle remained at a short length, the contractile filaments would be oriented so as to maximize force development by shorter thicker muscle cells; whereas when the muscle cell was stretched to longer lengths, the organization of the contractile elements would be adjusted to optimize force development to the longer thinner conformation of the smooth muscle cell. Thus stretch or length oscillation to a longer length would reduce the stiffness and active force of the muscle (fig. 7).

The observed effects of lung volume changes on airway tone in vivo can be interpreted in terms of these cellular mechanisms. During prolonged tidal breathing at functional residual capacity (FRC), the cytoskeletal lattice of the muscle cells would remodel to adapt to the shorter length of the muscle cells, thus making the muscle stiffer and increasing its contractility. Deep inspiration would stretch the muscle to a longer length, forcing the cytoskeletal framework to lengthen and thereby reducing muscle stiffness (fig. 8). When tidal breathing at FRC was subsequently resumed after a deep breath, muscle contractility and stiffness would remain lower for some time until the cytoskeletal organization of the muscle remodelled to adapt to the shorter length. Airway muscle contractility would therefore be a function of end inspiratory volume: the greater the stretch on the airways during breathing, the more muscle stiffness and contractility would be reduced. The amount of airway narrowing and stretch that occurred during a single breathing cycle

a)

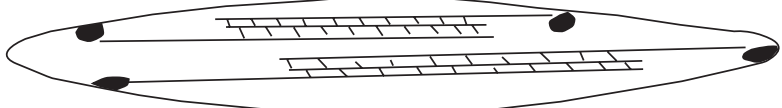

b)
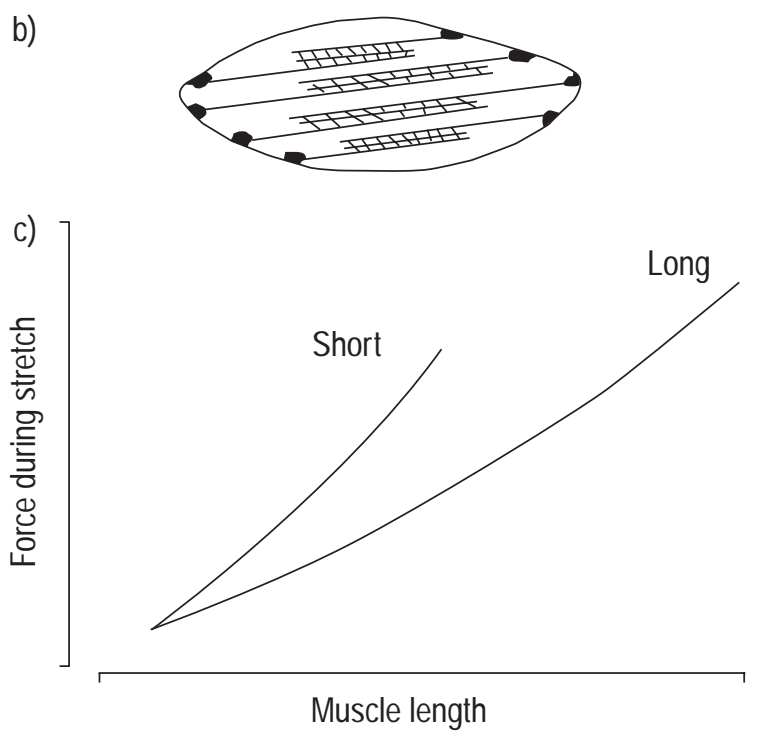

Fig. 7. - Theoretical effect of contractile filament reorganization on muscle stiffness. Contraction of muscle cell at a short length (b) would result in more contractile filaments in parallel making the muscle cell stiffer than after contraction at a long length (a). 

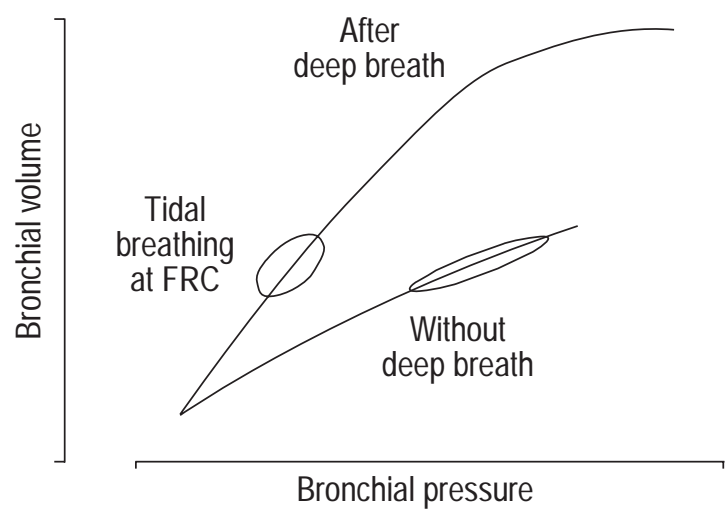

Fig. 8. - Mechanical modulation of airway contractility and compliance. In the absence of a deep breath, the airway smooth muscle cell would be stiffer and more contractile due to remodelling of the organization of contractile filaments. This would result in lower airway compliance and higher airway reactivity during tidal breathing at functional residual capacity (FRC). Deep inspiration would stretch the smooth muscle cells, forcing contractile filament organization to adapt to longer thinner muscle cells. This would result in an increase in airway compliance and a reduction in airway contractility when tidal breathing was resumed at FRC.

would be determined by the frequency of the volume cycle $[191,198]$. When the average rate of airway muscle length change was significantly slower than the shortening velocity of the muscle, active shortening of the contractile element could occur during the breathing cycle and thereby increase force [198, 200]. Thus, stretch of the airways smooth muscle that occurred during breathing would affect airway smooth muscle narrowing by a combination of effects on crossbridge cycling and contractile filament organization.

\section{Future directions}

The contractile properties of airway smooth muscle are a fundamental determinant of airway responsiveness in vivo. Mechanical influences on the airways during breathing clearly play an important role in regulating airway tone in vivo, yet the mechanisms for some of the most basic functional properties of airway smooth muscle remain to be established. The length-dependence of smooth muscle contractility has been recognized for decades, and it forms an essential foundation for many aspects of the physiological regulation of airway contractility in vivo. Although the length-sensitivity of contractile force has traditionally been interpreted in the context of the sliding filament model developed to explain the length-tension properties of skeletal muscle, this model cannot account for some of the unique functional properties of smooth muscle. It is also difficult to interpret this model in terms of the specialized contractile filament organization of smooth muscle.

Emerging evidence suggests that the length-sensitivity of contractile force in smooth muscle may be mediated in part by mechanosensitive signalling pathways that regulate the activation of contractile proteins as well as the orga- nization of the contractile elements within the cell. In nonmuscle cells, mechanosensitive signalling pathways regulate cell proliferation and phenotype, as well as acute functional responses such as cell motility and secretion. In airway smooth muscle, mechanosensitive signalling pathways may interconnect molecular events that regulate the activation of contractile proteins to those that modulate cellular organization. These pathways may also lead to the modulation of smooth muscle cell phenotype and tissue architecture in response to mechanical forces. The interplay between signalling pathways that regulate smooth muscle cell and tissue structure, phenotype and contractility will be important for understanding the changes in airway structure and contractility that underlie pathophysiological conditions of airway hyperresponsiveness.

Acknowledgements. The authors thank M-F. $\mathrm{Wu}$ for assistance in preparation of the figures.

\section{References}

1. Huxley AF, Niedergerke R. Structural changes in muscle during contraction. Nature 1954; 173: 971-972.

2. Huxley HE, Hanson EJ. Changes in cross-striations of muscle during contraction and stretch and their structural interpretation. Nature 1954; 173: 973-976.

3. Stephens NL, Van Niekerk W. Isometric and isotonic contractions in airway smooth muscle. Can J Physiol Pharmacol 1977; 55: 833-838.

4. Gabella G. Structural apparatus for force transmission in smooth muscles. Physiol Rev 1984; 64: 455-477.

5. Cooke PH, Kargacin G, Craig R, Fogarty K, Fay FS. Molecular structure and organization of filaments in single, skinned smooth muscle cells. Prog Clin Biol Res 1987; 245: 1-25.

6. Ashton FT, Somlyo AV, Somlyo AP. The contractile apparatus of vascular smooth muscle: intermediate high voltage stereo electron microscopy. J Mol Biol 1975; 98: $17-29$.

7. Somlyo AV. Ultrastructure of vascular smooth muscle. In: Bohr DF, Somlyo AP, Sparks HV, eds. The Cardiovascular System. American Physiological Society, Bethesda, MD, 1980; pp. 33-67.

8. Stephens NL, Kroeger EA. Ultrastructure, biophysics, and biochemistry of airway smooth muscle. In: Nadel JA, ed. Physiology and Pharmacology of Airways. Marcel Dekker, New York, NY, USA, 1980; pp. 31-121.

9. Nonomura J. Fine structure of myofilaments in chicken gizzard smooth muscle. In: Yamada E, Mazuhira K, Kurosumi K, Nagano T, eds. Recent Progress in Electron Microscopy of Cells and Tissues. Stuttgart, West Germany, Thieme, 1976; pp. 40-48.

10. Somlyo AP, Devine CE, Somlyo AV, Rice RV. Filament organization in vertebrate smooth muscle. Philos Tans $R$ Soc Lond Biol Sci 1973; 265: 223-229.

11. Bennett GS, Fellini SA, Croop JM, Otto JJ, Bryan J, Holtzer H. Differences among 100-A filamentilament subunits from different cell types. Proc Natl Acad Sci USA 1978; 75: 4364-4368.

12. Frank ED, Warren L. Aortic smooth muscle cells contain vimentin instead of desmin. Proc Natl Acad Sci USA 1981; 78: 3020-3024. 
13. Bagby RM. Ultrastructure, cytochemistry, and organization of myofilaments in vertebrate smooth muscle cells. In: Motta PM, ed. Ultrastructure of Smooth Muscle. Kluwer Academic Publishers, Boston, MA, 1990; pp. 2361.

14. Park S, Rasmussen H. Carbachol-induced protein phosphorylation changes in bovine tracheal smooth muscle. $J$ Biol Chem 1986; 261: 15734-15739.

15. Tsukita S, Ishikawa H. Association of actin and $10 \mathrm{~nm}$ filaments with the dense body in smooth muscle cells of the chicken gizzard. Cell Tissue Res 1983; 229: 233-242.

16. Draeger A, Amos WB, Ikebe M, Small JV. The cytoskeletal and contractile apparatus of smooth muscle: contraction bands and segmentation of the contractile elements. J Cell Biol 1990; 111: 2463-2473.

17. Lafont F, Toldo L. Cytoskeleton. Curr Opin Cell Biol 1997; 9: 118

18. Small JV. Geometry of actin-membrane attachments in the smooth muscle cell: the localisations of vinculin and alpha-actinin. EMBO J 1985; 4: 45-49.

19. Pease DC, Molinari S. Electron microscopy of muscular arteries; pial vessels of the cat and monkey. J Ultrastruct Res 1960; 3: 447-468.

20. Gabella G. General aspects of the fine structure of smooth muscles. In: Motta PM, ed. Ultrastructure of Smooth Muscle. Kluwer Academic Publishers, Boston, 1990; pp. $1-22$.

21. Inoue T. The three-dimensional ultrastructure of intracellular organization of smooth muscle cells by scanning electron microscopy. In: Motta PM, ed. Ultrastructure of Smooth Muscle. Kluwer Academic Publishers, Boston, MA, 1990; pp. 63-77.

22. Draeger A, Stelzer EH, Herzog M, Small JV. Unique geometry of actin-membrane anchorage sites in avian gizzard smooth muscle cells. J Cell Sci 1989; 94: 703711.

23. Fay FS, Fujiwara K, Rees DD, Fogarty KE. Distribution of alpha-actinin in single isolated smooth muscle cells. $J$ Cell Biol 1983; 96: 783-795.

24. Turner CE, Burridge K. Transmembrane molecular assemblies in cell-extracellular matrix interactions. Curr Opin Cell Biol 1991; 3: 849-853.

25. Drenckhahn D, Beckerle M, Burridge K, Otto J. Identification and subcellular location of talin in various cell types and tissues by means of ${ }^{125} \mathrm{I}$ vinculin overlay, immunoblotting and immunocytochemistry. Eur $J$ Cell Biol 1988; 46: 513-522.

26. Geiger B, Dutton AH, Tokuyasu KT, Singer SJ. Immunoelectron microscope studies of membrane-microfilament interactions: distributions of alpha-actinin, tropomyosin, and vinculin in intestinal epithelial brush border and chicken gizzard smooth muscle cells. J Cell Biol 1981; 91: 614-628.

27. Turner CE, Kramarcy N, Sealock R, Burridge K. Localization of paxillin, a focal adhesion protein, to smooth muscle dense plaques, and the myotendinous and neuromuscular junctions of skeletal muscle. Exp Cell Res 1991; 192: 651-655.

28. Kargacin GJ, Cooke PH, Abramson SB, Fay FS. Periodic organization of the contractile apparatus in smooth muscle revealed by the motion of dense bodies in single cells. J Cell Biol 1989; 108: 1465-1475.

29. Burridge K, Chrzanowska-Wodnicka M. Focal adhesions, contractility, and signaling. Annu Rev Cell Dev Biol 1996; 12: 463-51.

30. Lewis JM, Schwartz MA. Mapping in vivo associations of cytoplasmic proteins with integrin beta 1 cytoplasmic domain mutants. Mol Biol Cell 1995; 6: 151-160.

31. Schwartz MA, Schaller MD, Ginsberg MH. Integrins: emerging paradigms of signal transduction. Annu Rev Cell Dev Biol 1995; 11: 549-599.

32. McGregor A, Blanchard AD, Rowe AJ, Critchley DR. Identification of the vinculin-binding site in the cytoskeletal protein alpha-actinin. Biochem J 1994; 301: 225233.

33. Otey CA, Vasquez GB, Burridge K, Erickson BW. Mapping of the alpha-actinin binding site within the beta 1 integrin cytoplasmic domain. $J$ Biol Chem 1993; 268: 21193-21197.

34. Pavalko FM, LaRoche SM. Activation of human neutrophils induces an interaction between the integrin beta 2 -subunit (CD18) and the actin binding protein alpha-actinin. J Immunol 1993; 151: 3795-3807.

35. Retta SF, Barry ST, Critchley DR, Defilippi P, Silengo L, Tarone G. Focal adhesion and stress fiber formation is regulated by tyrosine phosphatase activity. Exp Cell Res 1996; 229: 307-317.

36. Hartwig JH. Mechanisms of actin rearrangements mediating platelet activation. J Cell Biol 1992; 118: 1421-1442.

37. Theriot JA. Regulation of the actin cytoskeleton in living cells. Semin Cell Biol 1994; 5: 193-199.

38. Bond M, Somlyo AV. Dense bodies and actin polarity in vertebrate smooth muscle. J Cell Biol 1982; 95: 403-413.

39. Small JV. Structure-function relationships in smooth muscle: the missing links. Bioessays 1995; 17: 785-792.

40. North AJ, Gimona M, Lando Z, Small JV. Actin isoform compartments in chicken gizzard smooth muscle cells. $J$ Cell Sci 1994; 107: 445-455.

41. North AJ, Gimona M, Cross RA, Small JV. Calponin is localised in both the contractile apparatus and the cytoskeleton of smooth muscle cells. J Cell Sci 1994; 107: 437-444.

42. Mabuchi K, Li Y, Tao T, Wang CL. Immunocytochemical localization of caldesmon and calponin in chicken gizzard smooth muscle. J Muscle Res Cell Motil 1996; 17: 243260.

43. Mabuchi K, Li B, Ip W, Tao T. Association of calponin with desmin intermediate filaments. J Biol Chem 1997; 272: 22662-22666.

44. Adelstein RS, Sellers JR. Myosin structure and function. In: Barany $\mathrm{M}$, ed. Biochemistry of Smooth Muscle Contraction. Academic Press Inc., San Diego, CA, 1996; pp. 3-19.

45. Warrick HM, Spudich JA. Myosin structure and function in cell motility. Annu Rev Cell Biol 1987; 3: 379-421.

46. Rayment I, Smith C, Yount RG. The active site of myosin. Annu Rev Physiol 1996; 58: 671-702.

47. Rayment I, Rypniewski WR, Schmidt-Base K, et al. Three-dimensional structure of myosin subfragment-1: a molecular motor. Science 1993; 261: 50-58.

48. Guilford WH, Dupuis DE, Kennedy G, Wu J, Patlak JB, Warshaw DM. Smooth muscle and skeletal muscle myosins produce similar unitary forces and displacements in the laser trap. Biophys $J$ 1997; 72: 1006-1021.

49. Wagner PD, Giniger E. Hydrolysis of ATP and reversible binding to F-actin by myosin heavy chains free of all light chains. Nature 1981; 292: 560-562.

50. Sivaramakrishnan M, Burke M. The free heavy chain of vertebrate skeletal myosin subfragment 1 shows full enzymatic activity. $J$ Biol Chem 1982; 257: 1102-1105.

51. Hartshorne DJ. Biochemistry of the contractile process in smooth muscle. In: Johnson L, ed. Physiology of the 
Gastrointestinal Tract. 2nd Edn. Raven Press, New York, NY, 1987; pp. 423-482.

52. Scholey JM, Taylor KA, Kendrick-Jones J. Regulation of non-muscle myosin assembly by calmodulin-dependent light chain kinase. Nature 1980; 287: 233-235.

53. Scholey JM, Taylor KA, Kendrick-Jones J. The role of myosin light chains in regulating actin-myosin interaction. Biochimie 1981; 63: 255-271.

54. Suzuki H, Onishi H, Takahashi K, Watanabe S. Structure and function of chicken gizzard myosin. J Biochem 1978; 84: $1529-1542$.

55. Trybus KM, Huiatt TW, Lowey S. A bent monomeric conformation of myosin from smooth muscle. Proc Natl Acad Sci USA 1982; 79: 6151-6155.

56. Trybus KM, Lowey S. Conformational states of smooth muscle myosin: effects of light chain phosphorylation and ionic strength. J Biol Chem 1984; 259: 8564-8571.

57. Craig R, Smith R, Kendrick-Jones J. Light-chain phosphorylation controls the conformation of vertebrate nonmuscle and smooth muscle myosin molecules. Nature 1983; 302: 436-439.

58. Smith RC, Cande WZ, Craig R, Tooth PJ, Scholey JM, Kendrick-Jones J. Regulation of myosin filament assembly by light-chain phosphorylation. Philos Trans $R$ Soc Lond B Biol Sci 1983; 302: 73-82.

59. Kendrick-Jones J, Smith RC, Craig R, Citi S. Polymerization of vertebrate non-muscle and smooth muscle myosins. J Mol Biol 1987; 198: 241-252.

60. Trybus KM. Filamentous smooth muscle myosin is regulated by phosphorylation. J Cell Biol 1989; 109: 28872894.

61. Trybus KM, Lowey S. Assembly of smooth muscle myosin minifilaments: effects of phosphorylation and nucleotide binding. J Cell Biol 1987; 105: 3007-3019.

62. Cross RA, Vandekerckhove J. Solubility-determining domain of smooth muscle myosin rod. FEBS Lett 1986; 200: 355-360.

63. Xu JQ, Gillis JM, Craig R. Polymerization of myosin on activation of rat anococcygeus smooth muscle. J Muscle Res Cell Motil 1997; 18: 381-393.

64. Gillis JM, Cao ML, Godfraind-De Becker A. Density of myosin filaments in the rat anococcygeus muscle, at rest and in contraction. II. J Muscle Res Cell Motil 1988; 9: $18-29$.

65. Godfraind-De Becker A, Gillis JM. Analysis of the birefringence of the smooth muscle anococcygeus of the rat, at rest and in contraction. I. J Muscle Res Cell Motil 1988; 9: 9-17.

66. Horowitz A, Trybus KM, Bowman DS, Fay FS. Antibodies probe for folded monomeric myosin in relaxed and contracted smooth muscle. J Cell Biol 1994; 126: 11951200 .

67. Cooke PH, Fay FS, Craig R. Myosin filaments isolated from skinned amphibian smooth muscle cells are sidepolar. J Muscle Res Cell Motil 1989; 10: 206-220.

68. Xu JQ, Harder BA, Uman P, Craig R. Myosin filament structure in vertebrate smooth muscle. J Cell Biol 1996; 134: 53-66.

69. Craig R, Megerman J. Assembly of smooth muscle myosin into side-polar filaments. J Cell Biol 1977; 75: 990-996.

70. Janmey PA, Hvidt S, Lamb J, Stossel TP. Resemblance of actin-binding protein/actin gels to covalently crosslinked networks. Nature 1990; 345: 89-92.

71. Lees-Miller JP, Heeley DH, Smillie LB. An abundant and novel protein of $22 \mathrm{kDa}$ (SM22) is widely distributed in smooth muscles. Purification from bovine aorta. Biochem $J$ 1987; 244: 705-709.

72. Kobayashi R, Kubota T, Hidaka H. Purification, characterization, and partial sequence analysis of a new 25-kDa actin-binding protein from bovine aorta: a SM22 homolog. Biochem Biophys Res Commun 1994; 198: 1275-1280.

73. Lin Pj, Luby-Phelps K, Stull JT. Binding of myosin light chain kinase to cellular actin-myosin filaments. $J$ Biol Chem 1997; 272: 7412-7420.

74. Larsen JK, Yamboliev IA, Weber LA, Gerthoffer WT. Phosphorylation of the 27-kDa heat shock protein via $\mathrm{p} 38$ MAP kinase and MAPKAP kinase in smooth muscle. Am J Physiol 1997; 273: L930-L940.

75. Benndorf R, Hayess K, Ryazantsev S, Wieske M, Behlke J, Lutsch G. Phosphorylation and supramolecular organization of murine small heat shock protein HSP25 abolish its actin polymerization-inhibiting activity. $J$ Biol Chem 1994; 269: 20780-20784.

76. Milligan RA, Whittaker M, Safer D. Molecular structure of F-actin and location of surface binding sites. Nature 1990; 348: 217-221.

77. Holmes KC, Popp D, Gebhard W, Kabsch W. Atomic model of the actin filament. Nature 1990; 347: 44-49.

78. Kabsch W, Mannherz HG, Suck D, Pai EF, Holmes KC. Atomic structure of the actin: DNase I complex. Nature 1990; 347: 37-44.

79. Kabsch W, Vandekerckhove J. Structure and function of actin. Annu Rev Biophys Biomol Struct 1992; 21: 49-76.

80. Halayko AJ, Salari H, MA X, Stephens NL. Markers of airway smooth muscle cell phenotype. Am J Physiol 1996; 270: L1040-L1051.

81. Wong JZ, Woodcock-Mitchell J, Mitchell J, et al. Smooth muscle actin and myosin expression in cultured airway smooth muscle cells. Am J Physiol 1998; 274: L786L792.

82. Lehman W, Sheldon A, Madonia W. Diversity in smooth muscle thin filament composition. Biochim Biophys Acta 1987; 914: 35-39.

83. Pollard TD, Cooper JA. Actin and actin-binding proteins: a critical evaluation of mechanisms and functions. Annu Rev Biochem 1986; 55: 987-1035.

84. Schafer DA, Hug C, Cooper JA. Inhibition of CapZ during myofibrillogenesis alters assembly of actin filaments. J Cell Biol 1995; 128: 61-70.

85. Zigmond SH. Signal transduction and actin filament organization. Curr Opin Cell Biol 1996; 8: 66-73.

86. Hinssen H, Small JV, Sobieszek A. A $\mathrm{Ca}^{2+}$-dependent actin modulator from vertebrate smooth muscle. FEBS Lett 1984; 166: 90-95.

87. Buss F, Jockusch BM. Tissue-specific expression of profilin. FEBS Lett 1989; 249: 31-34.

88. Mehta D, Gunst SJ. Actin polymerization stimulated by contractile activation regulates force development in canine tracheal smooth muscle. J Physiol 1999; 519: 829-840.

89. Sobieszek A, Bremel RD. Preparation and properties of vertebrate smooth-muscle myofibrils and actomyosin. Eur J Biochem 1975; 55: 49-60.

90. Moore PB, Huxley HE, DeRosier DJ. Three-dimensional reconstruction of $\mathrm{F}$-actin, thin filaments and decorated thin filaments. J Mol Biol 1970; 50: 279-295.

91. O'Brien EJ, Bennett PM, Hanson J. Optical diffraction studies of myofibrillar structure. Philos Trans $R$ Soc Lond B Biol Sci 1971; 261: 201-208.

92. Spudich JA, Huxley HE, Finch JT. Regulation of skeletal muscle contraction. II. Structural studies of the interaction 
of the tropomyosin-troponin complex with actin. $J \mathrm{Mol}$ Biol 1972; 72: 619-632.

93. Lehman W, Craig R, Vibert P. Ca2 $2^{+}$-induced tropomyosin movement in Limulus thin filaments revealed by three-dimensional reconstruction. Nature 1994; 368: 6567.

94. Moody C, Lehman W, Craig R. Caldesmon and the structure of smooth muscle thin filaments: electron microscopy of isolated thin filaments. J Muscle Res Cell Motil 1990; 11: 176-185.

95. Vibert $\mathrm{P}$, Craig R, Lehman W. Three-dimensional reconstruction of caldesmon-containing smooth muscle thin filaments. J Cell Biol 1993; 123: 313-321.

96. Marston SB, Redwood CS. The essential role of tropomyosin in cooperative regulation of smooth muscle thin filament activity by caldesmon. $J$ Biol Chem 1993; 268 : 12317-12320.

97. Gerthoffer WT, Pohl J. Caldesmon and calponin phosphorylation in regulation of smooth muscle contraction. Can J Physiol Pharmacol 1994; 72: 1410-1414.

98. Ngai PK, Walsh MP. The effects of phosphorylation of smooth-muscle caldesmon. Biochem J 1987; 244: 417425.

99. Smith CW, Pritchard K, Marston SB. The mechanism of $\mathrm{Ca}^{2+}$ regulation of vascular smooth muscle thin filaments by caldesmon and calmodulin. J Biol Chem 1987; 262: 116-122.

100. Ngai PK, Walsh MP. Inhibition of smooth muscle actinactivated myosin $\mathrm{Mg}^{2+}$-ATPase activity by caldesmon. $J$ Biol Chem 1984; 259: 13656-13659.

101. Marston SB, Lehman W. Caldesmon is a $\mathrm{Ca}^{2+}$-regulatory component of native smooth-muscle thin filaments. Biochem J 1985; 231: 517-522.

102. Chalovich JM, Cornelius P, Benson CE. Caldesmon inhibits skeletal actomyosin subfragment-1 ATPase activity and the binding of myosin subfragment-1 to actin. $J$ Biol Chem 1987; 262: 5711-5716.

103. Marston SB, Smith CW. The thin filaments of smooth muscles. J Muscle Res Cell Motil 1985; 6: 669-708.

104. Sobue K, Morimoto K, Kanda K, Maruyama K, Kakiuchi $\mathrm{S}$. Reconstitution of $\mathrm{Ca}^{2+}$-sensitive gelation of actin filaments with filamen, caldesmon and calmodulin. FEBS Lett 1982; 138: 289-292.

105. Walsh MP, Carmichael JD, Kargacin GJ. Characterization and confocal imaging of calponin in gastrointestinal smooth muscle. Am J Physiol 1993; 265: C1371-C1378.

106. Winder SJ, Walsh MP. Smooth muscle calponin: inhibition of actomyosin MgATPase and regulation by phosphorylation. J Biol Chem 1990; 265: 10148-10155.

107. Gimona M, Small JV. Calponin. In: Barany M, ed. Biochemistry of Smooth Muscle Contraction. Academic Press Inc., San Diego, CA, 1996; pp. 91-103.

108. Shirinsky VP, Biryukov KG, Hettasch JM, Sellers JR. Inhibition of the relative movement of actin and myosin by caldesmon and calponin. $J$ Biol Chem 1992; 267: 15886-15892.

109. Haeberle JR, Trybus KM, Hemric ME, Warshaw DM. The effects of smooth muscle caldesmon on actin filament motility. J Biol Chem 1992; 267: 23001-23006.

110. Makuch R, Birukov K, Shirinsky V, Dabrowska R. Functional interrelationship between calponin and caldesmon. Biochem J 1991; 280: 33-38.

111. Small JV, Furst DO, De Mey J. Localization of filamin in smooth muscle. J Cell Biol 1986; 102: 210-220.

112. Furst DO, Cross RA, De Mey J, Small JV. Caldesmon is an elongated, flexible molecule localized in the actomyosin domains of smooth muscle. EMBOJ 1986; 5: 251-257.
113. Hodgkinson JL, el-Mezgueldi M, Craig R, Vibert P, Marston SB, Lehman W. 3-D image reconstruction of reconstituted smooth muscle thin filaments containing calponin: visualization of interactions between F-actin and calponin. J Mol Biol 1997; 273: 150-159.

114. Kamm KE, Stull JT. Activation of smooth muscle contraction: relation between myosin phosphorylation and stiffness. Science 1986; 232: 80-82.

115. Kamm KE, Stull JT. Myosin phosphorylation, force, and maximal shortening velocity in neurally stimulated tracheal smooth muscle. Am J Physiol 1985; 249: C238C247.

116. Word RA, Tang DC, Kamm KE. Activation properties of myosin light chain kinase during contraction/relaxation cycles of tonic and phasic smooth muscles. J Biol Chem 1994; 269: 21596-21602.

117. Kamm KE, Stull JT. The function of myosin and myosin light chain kinase phosphorylation in smooth muscle. Annu Rev Pharmacol Toxicol 1985; 25: 593-620.

118. Somlyo AP, Somlyo AV. Signal transduction and regulation in smooth muscle. Nature 1994; 372: 231-236.

119. Tanner JA, Haeberle JR, Meiss RA. Regulation of glycerinated smooth muscle contraction and relaxation by myosin phosphorylation. Am J Physiol 1988; 255: C34C42.

120. Dillon PF, Aksoy MO, Driska SP, Murphy RA. Myosin phosphorylation and the cross-bridge cycle in arterial smooth muscle. Science 1981; 211: 495-497.

121. Hai CM, Murphy RA. Regulation of shortening velocity by cross-bridge phosphorylation in smooth muscle. $A m J$ Physiol 1988; 255: C86-C94.

122. Hai CM, Murphy RA. Cross-bridge phosphorylation and regulation of latch state in smooth muscle. Am J Physiol 1988; 254: C99-C106.

123. Hai CM, Murphy RA. Cross-bridge dephosphorylation and relaxation of vascular smooth muscle. Am J Physiol 1989; 256: C282-C287.

124. Murphy RA. Contraction in smooth muscle cells. Annu Rev Physiol 1989; 51: 275-283.

125. Gerthoffer WT, Murphy RA. Myosin phosphorylation and regulation of cross-bridge cycle in tracheal smooth muscle. Am J Physiol 1983; 244: C182-C187.

126. Merkel L, Gerthoffer WT, Torphy TJ. Dissociation between myosin phosphorylation and shortening velocity in canine trachea. Am J Physiol 1990; 258: C524-C532.

127. Gunst SJ, al-Hassani MH, Adam LP. Regulation of isotonic shortening velocity by second messengers in tracheal smooth muscle. Am J Physiol 1994; 266: C684C691.

128. Gunst SJ, Gerthoffer WT, al-Hassani MH. $\mathrm{Ca}^{2+}$ sensitivity of contractile activation during muscarinic stimulation of tracheal muscle. Am J Physiol 1992; 263: C1258-C1265.

129. Gerthoffer WT. Dissociation of myosin phosphorylation and active tension during muscarinic stimulation of tracheal smooth muscle. J Pharmacol Exp Ther 1987; 240: 815.

130. Gerthoffer WT, Murphey KA, Gunst SJ. Aequorin luminescence, myosin phosphorylation, and active stress in tracheal smooth muscle. Am J Physiol 1989; 257: C1062C1068.

131. Tang DC, Stull JT, Kubota Y, Kamm KE. Regulation of the $\mathrm{Ca}^{2+}$ dependence of smooth muscle contraction. J Biol Chem 1992; 267: 11839-11845.

132. Gunst SJ, Bandyopadhyay S. Contractile force and intracellular $\mathrm{Ca}^{2+}$ during relaxation of canine tracheal smooth muscle. Am J Physiol 1989; 257: C355-C364. 
133. Stull JT, Hsu LC, Tansey MG, Kamm KE. Myosin light chain kinase phosphorylation in tracheal smooth muscle. J Biol Chem 1990; 265: 16683-16690.

134. Tansey MG, Luby-Phelps K, Kamm KE, Stull JT. $\mathrm{Ca}^{2+}$ dependent phosphorylation of myosin light chain kinase decreases the $\mathrm{Ca}^{2+}$ sensitivity of light chain phosphorylation within smooth muscle cells. J Biol Chem 1994; 269: 9912-9920.

135. Stull JT, Tansey MG, Tang DC, Word RA, Kamm KE. Phosphorylation of myosin light chain kinase: a cellular mechanism for $\mathrm{Ca}^{2+}$ desensitization. Mol Cell Biochem 1993; 127/128: 229-237.

136. Kamm KE, Stull JT. Regulation of smooth muscle contractile elements by second messengers. Annu Rev Physiol 1989; 51: 299-313.

137. Mehta D, Wu MF, Gunst SJ. $\mathrm{Ca}^{2+}$ sensitivity of tyrosine phosphorylation of paxillin and myosin light chain phosphorylation in beta-escin permeabilized canine tracheal smooth muscle. Biophys J 1997; 72: A117.

138. Tang D, Gunst SJ. Ca ${ }^{2+}$-independent myosin light chain phosphorylation is not length-sensitive in permeabilized airway smooth muscle. Am J Respir Crit Care Med 1999; 159: A470.

139. Akao M, Hirasaki A, Jones KA, Wong GY, Bremerich $\mathrm{DH}$, Warner DO. Halothane reduces myofilament $\mathrm{Ca}^{2+}$ sensitivity during muscarinic receptor stimulation of airway smooth muscle. Am J Physiol 1996; 271: L719L725.

140. Somlyo AP, Somlyo AV. From pharmacomechanical coupling to G-proteins and myosin phosphatase. Acta Physiol Scand 1998; 164: 437-448.

141. Kimura K, Ito M, Amano M, et al. Regulation of myosin phosphatase by Rho and Rho-associated kinase (Rhokinase). Science 1996; 273: 245-248.

142. Amano M, Ito M, Kimura K, et al. Phosphorylation and activation of myosin by Rho-associated kinase (Rhokinase). J Biol Chem 1996; 271: 20246-20249.

143. Wang Z, Jiang H, Yang ZQ, Chacko S. Both N-terminal myosin-binding and C-terminal actin-binding sites on smooth muscle caldesmon are required for caldesmonmediated inhibition of actin filament velocity. Proc Natl Acad Sci USA 1997; 94: 11899-11904.

144. Gerthoffer WT, Yamboliev IA, Pohl J, Haynes R, Dang S, McHugh J. Activation of MAP kinases in airway smooth muscle. Am J Physiol 1997; 272: L244-L252.

145. Pohl J, Winder SJ, Allen BG, Walsh MP, Sellers JR, Gerthoffer WT. Phosphorylation of calponin in airway smooth muscle. Am J Physiol 1997; 272: L115-L123.

146. Tang DC, Kang HM, Jin JP, Fraser ED, Walsh MP. Structure-function relations of smooth muscle calponin: the critical role of serine 175. J Biol Chem 1996; 271: 8605-8611.

147. Wang Z, Pavalko FM, Gunst SJ. Tyrosine phosphorylation of the dense plaque protein paxillin is regulated during smooth muscle contraction. Am J Physiol 1996; 271: C1594-C1602.

148. Tang D, Mehta D, Gunst SJ. Mechanosensitive tyrosine phosphorylation of paxillin and focal adhesion kinase in tracheal smooth muscle. Am J Physiol 1999; 276: C250C258.

149. Steusloff A, Paul E, Semenchuk LA, Di Salvo J, Pfitzer $\mathrm{G}$. Modulation of $\mathrm{Ca}^{2+}$ sensitivity in smooth muscle by genistein and protein tyrosine phosphorylation. Arch Biochem Biophys 1995; 320: 236-242.

150. Di Salvo J, Pfitzer G, Semenchuk LA. Protein tyrosine phosphorylation, cellular $\mathrm{Ca}^{2+}$, and $\mathrm{Ca}^{2+}$ sensitivity for contraction of smooth muscle. Can J Physiol Pharmacol 1994; 72: 1434-1439.

151. Gilmore AP, Romer LH. Inhibition of focal adhesion kinase (FAK) signaling in focal adhesions decreases cell motility and proliferation. Mol Biol Cell 1996; 7: 12091224.

152. Richardson A, Parsons T. A mechanism for regulation of the adhesion-associated proteintyrosine kinase pp125FAK (published erratum appears in Nature 1996 Jun 27; 381: 810). Nature 1996; 380: 538-540.

153. Richardson A, Malik RK, Hildebrand JD, Parsons JT. Inhibition of cell spreading by expression of the Cterminal domain of focal adhesion kinase (FAK) is rescued by coexpression of Src or catalytically inactive FAK: a role for paxillin tyrosine phosphorylation. Mol Cell Biol 1997; 17: 6906-6914.

154. Ilic D, Furuta Y, Kanazawa S, et al. Reduced cell motility and enhanced focal adhesion contact formation in cells from FAK-deficient mice. Nature 1995; 377: 539-544.

155. Mitchell RW, Ndukwu IM, Arbetter K, Solway J, Leff AR. Effect of airway inflammation on smooth muscle shortening and contractility in guinea pig trachealis. Am J Physiol 1993; 265: L549-L554.

156. Kong SK, Halayko AJ, Stephens NL. Increased myosin phosphorylation in sensitized canine tracheal smooth muscle. Am J Physiol 1990; 259: L53-L5.

157. Jiang H, Rao K, Halayko AJ, Liu X, Stephens NL. Ragweed sensitization-induced increase of myosin light chain kinase content in canine airway smooth muscle. $A m$ J Respir Cell Mol Biol 1992; 7: 567-573.

158. Stephens NL, Kroeger E, Mehta JA. Force-velocity characteristics of respiratory airway smooth muscle. $J$ Appl Physiol 1969; 26: 685-692.

159. Gunst SJ, Wu MF, Smith DD. Contraction history modulates isotonic shortening velocity in smooth muscle. Am J Physiol 1993; 265: C467-C476.

160. Gunst SJ, Stropp JQ. Pressure-volume and length-stress relationships in canine bronchi in vitro. J Appl Physiol 1988; 64: 2522-2531.

161. Gunst SJ, Lai-Fook SJ. Effect of inflation on trachealis muscle tone in canine tracheal segments in vitro. $J$ Appl Physiol: Respirat Environ Exercise Physiol 1983; 54: 906-913.

162. Price JM, Davis DL, Knauss EB. Length-dependent sensitivity in vascular smooth muscle. Am J Physiol 1981; 241: H557-H563.

163. Gunst SJ. Effect of length history on contractile behavior of canine tracheal smooth muscle. Am J Physiol 1986; 250: $\mathrm{C} 146-\mathrm{C} 154$.

164. Gordon AL, Huxley AF, Julian FJ. The variation of isometric tension with sarcomere length in vertebrate muscle fibres. J Physiol 1966; 184: 170-192.

165. Meiss RA. Limits to shortening in smooth muscle tissues. J Muscle Res Cell Motil 1992; 13: 190-198.

166. Meiss RA. Persistent mechanical effects of decreasing length during isometric contraction of ovarian ligament smooth muscle. J Muscle Res Cell Motil 1993; 14: 205218.

167. Meiss RA. Influence of intercellular tissue connections on airway muscle mechanics. J Appl Physiol 1999; 86: 515 .

168. Bramley AM, Roberts CR, Schellenberg RR. Collagenase increases shortening of human bronchial smooth muscle in vitro. Am J Respir Crit Care Med 1995; 152: 15131517.

169. Harris DE, Warshaw DM. Length versus active force 
relationship in single isolated smooth muscle cells. $\mathrm{Am} \mathrm{J}$ Physiol 1991; 260: C1104-C1112.

170. Mehta D, Wu MF, Gunst SJ. Role of contractile protein activation in the length-dependent modulation of tracheal smooth muscle force. Am J Physiol 1996; 270: C243C252.

171. Hai CM. Length-dependent myosin phosphorylation and contraction of arterial smooth muscle. Pflugers Arch 1991; 418: 564-571.

172. Yoo J, Ellis R, Morgan KG, Hai CM. Mechanosensitive modulation of myosin phosphorylation and phosphatidylinositol turnover in smooth muscle. Am J Physiol 1994; 267: C1657-C1665.

173. Rembold CM, Murphy RA. Muscle length, shortening, myoplasmic $\left[\mathrm{Ca}^{2+}\right]$, and activation of arterial smooth muscle. Circ Res 1990; 66: 1354-1361.

174. Wingard CJ, Browne AK, Murphy RA. Dependence of force on length at constant cross-bridge phosphorylation in the swine carotid media. J Physiol 1995; 488: 729-739.

175. Tseng S, Kim R, Kim T, Morgan KG, Hai CM. F-actin disruption attenuates agonist-induced $\left[\mathrm{Ca}^{2+}\right]$, myosin phosphorylation, and force in smooth muscle. Am J Physiol 1997; 272: C1960-C1967.

176. Pavalko FM, Adam LP, Wu MF, Walker TL, Gunst SJ. Phosphorylation of dense-plaque proteins talin and paxillin during tracheal smooth muscle contraction. $\mathrm{Am} \mathrm{J}$ Physiol 1995; 268: C563-C571.

177. Mehta D, Wang Z, Wu MF, Gunst SJ. Relationship between paxillin and myosin phosphorylation during muscarinic stimulation of smooth muscle. Am J Physiol 1998; 274: C741-C747.

178. Shyy JY, Chien S. Role of integrins in cellular responses to mechanical stress and adhesion. Curr Opin Cell Biol 1997; 9: 707-71.

179. Ingber DE. Tensegrity: the architectural basis of cellular mechanotransduction. Annu Rev Physiol 1997; 59: 575599.

180. Banes AJ, Tsuzaki M, Yamamoto J, et al. Mechanoreception at the cellular level: the detection, interpretation, and diversity of responses to mechanical signals. Biochem Cell Biol 1995; 73: 349-365.

181. Glogauer M, Arora P, Chou D, Janmey PA, Downey GP, McCulloch CA. The role of actin-binding protein 280 in integrin-dependent mechanoprotection. J Biol Chem 1998; 273: 1689-169.

182. Pratusevich VR, Seow CY, Ford LE. Plasticity in canine airway smooth muscle. J Gen Physiol 1995; 105: 73-94.

183. Ford LE, Seow CY, Pratusevich VR. Plasticity in smooth muscle, a hypothesis. Can J Physiol Pharmacol 1994; 72: $1320-1324$.

184. Gunst SJ. Effects of muscle length and load on intracellular $\mathrm{Ca}^{2+}$ in tracheal smooth muscle. Am J Physiol 1989; 256: C807-C812.

185. Gunst SJ, Meiss RA, Wu MF, Rowe M. Mechanisms for the mechanical plasticity of tracheal smooth muscle. Am J Physiol 1995; 268: C1267-C1276.
186. Malmberg P, Larsson K, Sundblad BM, Zhiping W. Importance of the time interval between FEV1 measurements in a methacholine provocation test. Eur Respir $J$ 1993; 6: 680-686.

187. Nadel JA, Tierney DF. Effect of a previous deep inspiration on airway resistance in man. J Appl Physiol 1961; 16: 717-719.

188. Fish JE, Ankin MG, Kelly JF, Peterman VI. Regulation of bronchomotor tone by lung inflation in asthmatic and nonasthmatic subjects. J Appl Physiol: Respirat Environ Exercise Physiol 1981; 50: 1079-1086.

189. Brusasco V, Crimi E, Barisione G, Spanevello A, Rodarte JR, Pellegrino R. Airway responsiveness to methacholine: effects of deep inhalations and airway inflammation. $J$ Appl Physiol 1999; 87: 567-573.

190. Warner DO, Gunst SJ. Limitation of maximal bronchoconstriction in living dogs. Am Rev Respir Dis 1992; 145: 553-560.

191. Tepper RS, Shen X, Bakan E, Gunst SJ. Maximal airway response in mature and immature rabbits during tidal ventilation. J Appl Physiol 1995; 79: 1190-1198.

192. Ingram RH Jr. Relationships among airway-parenchymal interactions, lung responsiveness, and inflammation in asthma. Giles F. Filley Lecture. Chest 1995; 107: 148S$152 \mathrm{~S}$.

193. King GG, Moore BJ, Pare PD. The time course of excessive airway narrowing caused by inhibition of deep inspirations during bronchoconstriction in normal subjects. Am J Respir Crit Med 1998; 157: A515.

194. Skloot G, Permutt S, Togias A. Airway hyperresponsiveness in asthma: a problem of limited smooth muscle relaxation with inspiration. J Clin Invest 1995; 96: 23932403.

195. Fredberg JJ. Airway smooth muscle in asthma: flirting with disaster. Eur Respir J 1998; 12: 1252-1256.

196. Gunst SJ, Stropp JQ, Service J. Mechanical modulation of pressure-volume characteristics of contracted canine airways in vitro. J Appl Physiol 1990; 68: 2223-2229.

197. Gunst SJ. Contractile force of canine airway smooth muscle during cyclical length changes. J Appl Physiol: Respirat Environ Exercise Physiol 1983; 55: 759-769.

198. Shen X, Wu MF, Tepper RS, Gunst SJ. Mechanisms for the mechanical response of airway smooth muscle to length oscillation. J Appl Physiol 1997; 83: 731-738.

199. Fredberg JJ, Inouye D, Miller B, et al. Airway smooth muscle, tidal stretches, and dynamically determined contractile states. Am J Respir Crit Care Med 1997; 156: 1752-1759.

200. Fredberg JJ, Inouye DS, Mijailovich SM, Butler JP. Perturbed equilibrium of myosin binding in airway smooth muscle and its implications in bronchospasm. Am J Respir Crit Care Med 1999; 159: 959-967.

201. Gunst SJ, Russell JA. Contractile force of canine tracheal smooth muscle during continuous stretch. J Appl Physiol: Respirat Environ Exercise Physiol 1982; 52: 655-663. 